\title{
LOS CRITERIOS JURISPRUDENCIALES PARA EXIGIR RESPONSABILIDAD PENAL A LAS PERSONAS JURÍDICAS EN EL DELITO CORPORATIVO
}

\author{
Miguel Ángel Morales Hernández \\ Becario de Investigación del Ministerio de Educación, Cultura y Deporte \\ para la Formación del Profesorado Universitario (FPU) \\ Departamento de Derecho Penal \\ Universidad de Granada
}

SUMARIO: 1. Introducción. 2. Una sentencia pionera. La Sentencia del Tribunal Supremo núm. 514/2015, de 2 de septiembre (Ponente: Excmo. Sr. Manuel Marchena Gómez). 3. La Sentencia del Tribunal Supremo núm. 154/2016, de 29 de febrero de 2016. "La Bisiesta» (Ponente: Excmo. Sr. José Manuel Maza Martín). 3.1 El supuesto de hecho. 3.2 Sobre el fundamento de la responsabilidad penal de las personas jurídicas y sobre la naturaleza de la exoneración de la responsabilidad penal de las personas jurídicas. 3.3 El régimen de responsabilidad de las personas jurídicas: requisitos y delito corporativo. 3.4 El problema de la carga de la prueba en la sentencia mayoritaria. 3.5 La emisión de un Voto Particular. 3.6. Una primera reflexión de la sentencia. La propuesta de una conciliación entre la sentencia mayoritaria y el Voto particular. 4. A vueltas con la responsabilidad penal de las personas jurídicas. La Sentencia del Tribunal Supremo núm. 221/2016, de 16 de marzo de 2016 (Ponente: Excmo. Sr. Manuel Marchena Gómez). 5. Una resolución singular: la sentencia del Tribunal Supremo núm. 516/2016, de 13 de junio de 2016 (Ponente: Excmo. Sr. Andrés Martínez Arrieta). 6. Los pronunciamientos posteriores del Tribunal Supremo en torno a esta cuestión. La reafirmación de su jurisprudencia. 7. La concreta estructura del delito corporativo reconocido por el Tribunal Supremo: el debate doctrinal. 8. Toma de posición. 9. Unas reflexiones a modo de conclusión.

Resumen: Las recientes reformas del Código Penal Español han supuesto una verdadera revolución en el ámbito de la responsabilidad penal de las personas jurídicas. A raíz de las mismas, el Tribunal Supremo ha dictado una serie de sentencias que han arrojado bastante luz acerca de cuáles han de ser los elementos o requisitos que configuran la base para la atribución de la responsabilidad penal a la persona jurídica. 
Analizando dichas sentencias, puede observarse el reconocimiento del delito corporativo, caracterizado por contar con sus propios elementos, distintos a los exigibles a las personas físicas. Pues bien: este trabajo tiene como principal objeto de estudio la doctrina del Tribunal Supremo sobre esta materia con la finalidad de inferir cuál es la posible configuración del delito corporativo en atención a estos pronunciamientos jurisprudenciales, a los principios del derecho penal, así como al propio tenor literal de la ley.

Ante esta situación, diferentes autores se han ido posicionando acerca de la fundamentación de la responsabilidad penal de las personas jurídicas; así como de la concreta estructura del delito corporativo. Se analizan también sus diferentes puntos de vista señalando que sus visiones del tema son muy dispares.

Palabras clave: Responsabilidad penal; personas jurídicas; Tribunal Supremo; delito corporativo; principios del derecho penal; Compliance; defecto de organización.

Abstract: Recent reforms of the Spanish Penal Code have supposed a real revolution in the area of criminal liability of legal entity. As a result of that, the Supreme Court has issued a series of judgments that shed light on which should be the elements or requirements that form the basis for the attribution of criminal responsibility to the legal entity.

Analyzing these jurisprudential pronouncements, we can observe the recognition of corporate crime, characterized by having its own elements, different from those required of natural persons. Well, this work has as its main object of study the doctrine of the Supreme Court on this matter with the purpose of inferring what is the possible configuration of the corporate crime in attention to these jurisprudential pronouncements, to the principles of criminal law, as well as to the own literal tenor of the law.

Faced with this situation, different authors have been positioning themselves on the basis of the criminal liability of legal entity; as well as the concrete structure of corporate crime. Their different points of view are also analyzed, pointing out that their views on the subject are very different.

Key words: Criminal liability; legal entity; Supreme Court; corporate crime; principles of criminal law; Compliance; organization defect.

\section{Introducción}

Hasta la reforma del Código Penal operada por la Ley Orgánica $5 / 2010$, a las personas jurídicas no se les hacía penalmente responsables de ningún hecho delictivo. Solamente se les podía imponer una serie de consecuencias accesorias (art. $129 \mathrm{CP}$ anterior a la reforma) deriva- 
das de un hecho delictivo cometido por otro ${ }^{1}$ o se les permitía hacerlas responsables solidarias del pago de las multas que se imponían a sus representantes cuando actuaran en su nombre en delitos especiales para garantizar su pago (artículo 31.2 CP, también anterior a la reforma).

Sin embargo, la Ley Orgánica 5/2010² introdujo en nuestro Código Penal a la persona jurídica como nuevo sujeto de responsabilidad penal, derogando el tradicional principio de «Societas delinquere non potest», sin perjuicio de la responsabilidad en la que puedan incurrir las personas físicas integrantes de aquéllas ${ }^{3}$. El legislador entendió que por razones de políticacriminal, se debía responsabilizar penalmente a las personas jurídicas dada sobre todo su proliferación en el ámbito de la delincuencia económica organizada (sistema de «numerus clausus») y la imposibilidad en muchos casos de poder determinar quién había sido la persona física que había delinquido en su seno, lo que podía provocar en estas circunstancias situaciones de auténtica impunidad ${ }^{4}$. Posteriormente, la LO 7/2012 incorporó a los partidos políticos como personas penalmente responsables. Y, finalmente, la LO. 1/2015, consolidó firmemente la apuesta del legislador por la exigencia de responsabilidad criminal de las personas jurídicas ${ }^{5}$. Se ha llegado a afirmar

1 Definidas por el Tribunal Supremo en la sentencia núm.480/2009 como «medidas de seguridad jurídico-penales».

2 Para cubrir lagunas tanto en aspectos sustantivos como procesales se hizo necesario la aprobación, primero, de la Ley 37/2011, de 10 de octubre, de medidas de agilización procesal -que introdujo los necesarios cambios en la Ley de Enjuiciamiento Criminal relativas a las implicaciones procesales del régimen de responsabilidad penal de las personas jurídicas-y, después, la Ley Orgánica 7/2012 que extendió la responsabilidad penal da las personas jurídicas a partidos políticos y sindicatos.

3 Así lo afirma Feisóo Sánchez, B. El delito corporativo en el Código Penal Español. Cizur Menor: Civitas, 2016, pp. 18-19. Este autor expone que «la principal novedad de la reforma de 2010 fue que por primera vez era posible hablar en propiedad de una responsabilidad penal propia o genuina de las personas jurídicas, con independencia de que se trata de una responsabilidad vinculada a la individual».

${ }_{4}$ Cuestión ampliamente abordada por la doctrina: Vid. RodRíguEz ALMIRón, F.J. La responsabilidad de las personas jurídicas a raíz de la jurisprudencia reciente de Tribunal Supremo. En Revista Aranzadi doctrinal, núm. 6/2017, parte Jurisprudencia, 29 de noviembre de 2017, p. 1. Para mayor profundidad vid. MARín DE EsPinosa CEBAllos, E.B. Criminalidad de empresa. La responsabilidad penal en las estructuras jerárquicamente organizadas. Valencia: Tirant lo Blanch, 2002, pp. 16-17 y 37-40. Vid., también, ZugALDía EsPinAR, J. M. La responsabilidad penal de empresas, fundaciones y asociaciones. Valencia: Tirant lo Blanch, 2008. p. 28. Allí, este autor afirma que «ante necesidades sociales cambiantes es deseable que las categorías dogmáticas se adapten a esas nuevas situaciones y exigencias político-criminales y que lo que es conveniente desde el punto de vista político criminal pueda resultar posible también desde el punto de vista dogmático». Vid., igualmente, Zugaldía EsPinar, J.M. La responsabilidad criminal de las personas jurídicas en el derecho penal español (análisis de la cuestión tras la reforma operada por la LO 1/2015, de 30 de marzo). En: MARÍN DE EsPINOSA CEBAllos, E. B (dir.) y Zugaldía EsPinAR, J.M (dir.). La responsabilidad criminal de las personas jurídicas en Latinoamérica y en España. Cizur menor: Aranzadi, 2015, pp. 219-220.

5 La mencionada reforma cubrió las importantes lagunas existentes, mejoró la regulación, incluyó a nuevos sujetos y delimitó el significado de conceptos y los requisitos de los modelos de organización y gestión. 
que a través de esta última reforma se ha intentado instaurar una verdadera cultura de respeto al derecho (Compliance) por parte de la empresa ${ }^{6}$.

Sin embargo, se debate acerca de si la ley configura un modelo de responsabilidad por el hecho propio de la persona jurídica ${ }^{7}-$ denominado modelo de autorresponsabilidad ${ }^{8}$ - o si, por el contrario, lo que ha instaurado es un modelo de transferencia de responsabilidad por el hecho de otro (de la persona física) ${ }^{9}$ o, también calificado, modelo de heterorresponsabilidad o responsabilidad vicarial ${ }^{10}$. Explica, en este sentido, ZugaLdía EsPINAR que los modelos de responsabilidad criminal indirecta o de heterorresponsabilidad (sistema vicarial) «implican que cuando un directivo o representante de una persona jurídica cometa un delito, éste debe imputarse a la persona jurídica (responsabilidad por "por reflejo o de rebote») siempre que se haya actuado en el giro de empresa y en beneficio de la misma» ${ }^{11}$. Por el contrario, los modelos

${ }^{6}$ Rodríguez Almirón, F.J. La responsabilidad de las personas jurídicas a raíz de la jurisprudencia reciente de Tribunal Supremo. Op. cit., p. 1.

${ }_{7}$ Firme defensor de este modelo es Gómez-JARA Díez, C. EL pleno jurisdiccional del Tribunal Supremo sobre responsabilidad penal de las personas jurídicas: fundamentos, voces discrepantes y propuesta reconciliadora. En Diario La Ley, núm. 8724, Sección Documento on-line, 17 de marzo de 2016, p. 2. Este autor afirma que «el modelo de responsabilidad por el hecho propio no sólo es el más respetuoso con los principios informadores del Derecho penal, sino que, además, obedece a una importante política-criminal y permite una adecuada vertebración de los derechos procesales de la persona jurídica».

8 Vid. Villegas García, M.A. Hacia un modelo de autorresponsabilidad de las personas jurídicas. La STS (Pleno de la Sala de lo Penal) 154/2016, de 29 de febrero. En Diario La Ley, núm. 8721, Sección Doctrina, 14 de marzo de 2016, p. 1. En palabras de este autor el modelo de autorresponsabilidad está "amparado en la culpabilidad de la propia organización y no en la de la persona física que cometió la infracción, que derivaría de la ausencia de controles efectivos para evitar la comisión de delitos en su seno».

9 En este sentido Vid. SILVA SÁnchez, J.M. La evolución ideológica de la discusión sobre la «responsabilidad penal de las personas jurídicas». En Derecho Penal y Criminología, Vol. 29, núm. 86-87, 2008, p. 133. El referido autor afirma que el modelo de responsabilidad por atribución presupone la comisión de un hecho delictivo por parte de personas físicas integrada en el seno de las persona jurídica (órgano o representante), de tal forma que «la responsabilidad por ese hecho delictivo se transfiere a la persona jurídica, en la medida en que se considera que los actos de dichos órganos, en virtud de la relación funcional existente entre éstos y aquélla, son, también, de esta última» quedando por resolver la cuestión del título por el cual se produce dicha transferencia de responsabilidad.

${ }_{10} \mathrm{Vid}$. Zugaldía EsPinaR, J. M. Modelos dogmáticos para exigir responsabilidad criminal a las personas jurídicas (a propósito de las SSTS de 2 de septiembre de 2015, de 29 de febrero de 2016 y 16 de marzo de 2016). En La Ley Penal, núm. 119, Sección Jurisprudencia aplicada a la práctica, Marzo-Abril 2016, pp. 1-3. Vid., también, en este sentido ZugaLdía ESPINAR, J.M. Teorías Jurídicas del delito de las personas jurídicas (aportaciones doctrinales y jurisprudenciales). Especial consideración de la teoría del hecho de conexión. En Cuadernos de Política Criminal núm. 121, Época II, Sección de Estudios Penales, mayo 2017, pp. 11-15. Este autor identifica dos modelos de este tipo de responsabilidad: el sistema vicarial y la teoría de la distribución de costes.

${ }_{11}$ Zugaldía EsPINAR, J.M. La responsabilidad criminal de las personas jurídicas, de los entes sin personalidad y de sus directivos. Valencia: Tirant lo Blanch, 2013, p. 58, con ulteriores citas a FEIJÓO SÁNCHEZ y NIETO MARTÍN. 
de autorresponsabilidad ofrecen un sistema de imputación propio de la persona jurídica en los que «la persona jurídica responde de su propia acción y por su propia culpabilidad, respetándose así los principios de personalidad de las penas y de culpabilidad. No se responde por el hecho de otro, ni la responsabilidad es objetiva» ${ }^{12}$. Es decir, es propiamente el ente colectivo el que comete el delito ${ }^{13}$.Ya el Preámbulo de la Ley de la reforma del Código Penal parece dejar meridianamente claro este asunto al poner de manifiesto que lo que se pretende a través de ella es poner fin a «las dudas interpretativas que había planeado la anterior regulación, que desde algunos sectores había sido interpretada como un régimen de responsabilidad vicarial».

En los últimos años, el Tribunal Supremo ha ido abordando distintos aspectos de esta materia y, que podemos calificar como esenciales en orden a determinar cuáles son los requisitos exigibles para que respondan penalmente las personas jurídicas o, dicho de otra firma, cuál es la concreta estructura de los que podemos denominar como «delito corporativo». Analizaremos este material jurisprudencial con el fin de determinar si se ha establecido una estructura dogmática propia, distinta y con genuinas características al cometido o cometidos por la persona físicas. No obstante, lo cierto es que, cómo podremos observar, los pronunciamientos de este órgano jurisdiccional no han terminado por esclarecer muchas de estas cuestiones, sino que, en realidad, no han hecho más que incrementar los problemas interpretativos y dogmáticos, llegando a existir claras discrepancias entre los propios miembros del Tribunal.

\section{Una sentencia Pionera. La sentencia del Tribunal Supremo núm. 514/2015, de 2 de septiembre (Ponente: Excmo. Sr. Manuel Marchena Gómez)}

El supuesto de hecho versa sobre un caso de estafa en el que el administrador de una persona jurídica se atribuye falsamente, sobre un bien inmueble, la facultad de arrendarla, de la cual carece, consiguiendo que una tercera persona le entregase una parte de lo solicitado.

12 Vid. Zugaldía Espinar, J. M. Modelos dogmáticos para exigir responsabilidad criminal a las personas jurídicas (a propósito de las SSTS de 2 de septiembre de 2015, de 29 de febrero de 2016 y 16 de marzo de 2016). Op. cit., pp. 3-4. Vid., también, Zugaldía EsPinar, J.M. Teorías Jurídicas del delito de las personas jurídicas (aportaciones doctrinales y jurisprudenciales). Especial consideración de la teoría del hecho de conexión. Op cit., pp. 9-33. Allí, este autor nos ofrece un análisis de los diversos grupos de modelos existentes con teorías de imputación muy diferentes: la teoría del dominio de la organización funcional sistemática, la teoría de los sistemas sociales autopoiéticos, la teoría de la acción comunicativa y la teoría del hecho de conexión.

13 Agudo Fernández, E; JaÉn Vallejo, M; Perrino Pérez, A.L. Capítulo IV. La responsabilidad penal de las personas jurídicas en la jurisprudencia. En Derecho penal de las personas jurídicas. Madrid: Dykinson, 2016, p. 124. 
Pese a que el recurrente no alegara un motivo que obligase a la Sala a pronunciarse sobre esta cuestión, el Tribunal, que hasta ese momento no había tenido todavía la oportunidad de pronunciarse sobre cuál es el fundamento de la responsabilidad penal de las personas jurídicas que se contemplaba en el artículo 31 bis, realiza una primera aproximación acerca de esta temática llegando a afirmar que:

«Ya se opte por un modelo de responsabilidad por el hecho propio, ya por una fórmula de heterorresponsabilidad, parece evidente que cualquier pronunciamiento condenatorio de las personas jurídicas habrá de estar basado en los principios irrenunciables que informan el Derecho penal» ${ }^{14}$.

Aunque bien es cierto que en esta pionera sentencia, nuestro más Alto Tribunal no se decanta por un modelo de responsabilidad por el hecho propio - de la persona jurídica- o de transferencia de responsabilidad por el hecho de otro —entendiéndose como el de la persona física一, como bien se apunta por la doctrina, al pronunciarse el Tribunal Supremo sobre la necesaria vigencia de los principios esenciales del Derecho Penal, parece descartarse de un modo implícito el modelo de heterorresponsabilidad ${ }^{15}$.

A pesar de esta vaguedad con la que la Sala se pronuncia por primera vez sobre esta cuestión, parece claro que principios como el de culpabilidad, el de exclusión de la responsabilidad objetiva y por el hecho ajeno y el principio ne bis in ídem van a resultar cruciales en la construcción de este nuevo régimen de responsabilidad que se atribuyen a estos entes colectivos ${ }^{16}$.

\section{La sentencia del Tribunal Supremo núm. 154/2016, de 29 de febrero de 2016. «La Bisiesta» (Ponente: Excmo. Sr. José Manuel Maza Martín)}

Es en esta resolución donde, por primera vez, el Alto Tribunal tiene la oportunidad de desarrollar de un modo minucioso la cuestión de la responsabilidad de las personas jurídicas a raíz de las modificaciones del Código Penal de 2015. Y debe subrayarse que, en opinión del TS,

${ }_{14}$ Fundamento de Derecho Tercero de la STS núm. 514/2015, de 2 de septiembre.

15 Agudo Fernández, E; JaÉn Vallejo, M; Perrino Pérez, A.L. Capítulo IV. La responsabilidad penal de las personas jurídicas en la jurisprudencia. Op cit., p. 122.

${ }^{16}$ En este sentido la doctrina se encuentra dividida. Vid. Del Rosal Blasco, B. Sobre los elementos estructurales de la responsabilidad penal de las personas jurídicas: reflexiones sobre la SSTS 154/2016 Y 221/2016 y sobre la Circular núm. 1/2016 de la Fiscalía General del Estado. En Diario la Ley, núm. 8732, Sección Doctrina, 1 de abril de 2016, p. 10. Este autor señala que hace falta un debate mucho más desarrollado sobre qué principios y derechos constitucionales del justiciable son aplicables a las personas jurídicas, porque, en su opinión, «no es tan meridianamente claro que todos los que son aplicables a la persona física deban de ser, también, aplicables a las personas jurídicas». 
el artículo 31 bis CP consagra un sistema de responsabilidad propio de la entidad, excluyendo un modelo de responsabilidad por hecho ajeno, modelo de responsabilidad vicarial o modelo de transferencia - de la responsabilidad de la persona física a la jurídica-.

\subsection{El supuesto de hecho}

En esta sentencia se juzgó un supuesto de tráfico de drogas. Se trataba de una organización criminal que se dedicaba a la exportación de maquinaria de obras públicas desde España a Venezuela, con la intención de una vez allí, introducir droga en su interior, para, con posterioridad, devolver la maquinaria de nuevo al país de origen.

Junto a varias personas físicas, se condenó por la Audiencia Nacional, el 17 de noviembre de 2014, a tres sociedades por un delito contra la salud pública.

Cabe destacar que una de las sociedades limitadas ejercía, además, actividades comerciales lícitas diversas y daba empleo a más de cien trabajadores; mientras que las otras dos eran personas jurídicas meramente instrumentales o pantalla, creadas exclusivamente para la comisión de los delitos por los que fueron condenadas, y no ejercían ninguna actividad comercial lícita conocida.

Asimismo, estas sociedades estaban dirigidas o administradas, de hecho, o de derecho, por alguno de los procesados también condenados como autores responsables del delito contra la salud pública.

La citada sentencia fue recurrida ante el Tribunal Supremo por todas las personas, tanto físicas como jurídicas, condenadas. Sin embargo, a pesar de los argumentos esgrimidos en los diversos recursos presentados, la Sala terminó confirmando la condena de estas tres sociedades y de las personas físicas que ostentaban su representación legal.

La presentación de recurso por parte de las sociedades condenadas en la anterior instancia fue lo que posibilitó que el Alto Tribunal tuviese la oportunidad, por primera vez, de manifestarse de forma expresa sobre el concreto sistema de responsabilidad penal de las personas jurídicas.

\subsection{Sobre el fundamento de la responsabilidad penal de las personas jurídicas y sobre la naturaleza de la exoneración de la responsabilidad penal de las personas jurídicas}

En una primera aproximación, el Tribunal Supremo vuelve a declarar -manteniendo el argumento de la STS 514/2015, que independientemente de cuál sea el sistema que fundamente la responsabilidad penal de 
las personas jurídicas, éste debe estar basado en los principios irrenunciables que informan el Derecho Penal ${ }^{17}$.

Sentado lo anterior, la Sala señala «que el sistema de responsabilidad penal de la persona jurídica se basa, sobre la previa constatación de la comisión de un delito por parte de la persona física integrante de la organización como presupuesto inicial de la referida responsabilidad, en la exigencia del establecimiento y correcta aplicación de medidas de control eficaces que prevengan e intenten evitar, en lo posible la comisión de infracciones delictiva por quienes integran la organización» ${ }^{18}$.

El Tribunal Supremo, en esta sentencia, confirma que el «déficit de control» es un elemento esencial de la Responsabilidad Penal de las personas jurídicas ${ }^{19}$. Esta idea, en la sentencia, se sintetiza del siguiente modo:

«Núcleo de la responsabilidad de la persona jurídica que, como venimos diciendo, no es otro que el de la ausencia de las medidas de control adecuadas para la evitación de la comisión de delitos, que evidencia en una voluntad seria de reforzar la virtualidad de la norma ${ }^{20}$.

En torno a esta cuestión el Alto Tribunal recalca que:

«Así, la determinación del actuar de la persona jurídica, relevante a efectos de la afirmación de su responsabilidad penal (incluido el supuesto del anterior art. 31 bis. 1 parr. $10^{\circ} \mathrm{CP}$ y hoy de forma definitiva a tenor del nuevo art. 31 bis. 1 a) y 2 CP, tras la reforma operada por la LO 1/2015), ha de establecerse a partir del análisis acerca de si el delito cometido por la personas física en el seno de aquella ha sido posible, o facilitado, por la ausencia de una cultura de respeto al derecho, como fuente de inspiración de la actuación de su estructura organizativa e independiente de la de cada una de las personas físicas que la integran, que habría de manifestarse en alguna clase de formas concretas de vigilancia y control del comportamiento de sus directivos y subordinados jerárquicos, tendentes a la evitación de la comisión por éstos de los delitos enumerados en el Libro II del Código Penal como posibles antecedentes de esta responsabilidad penal de la persona jurídica» ${ }^{21}$.

Utiliza, de esta manera, por primera vez, el Tribunal Supremo la expresión de «cultura de respeto al derecho». Podría entenderse, de este modo, que la ausencia de una cultura de respeto al derecho es el fundamento de

17 Fundamento de Derecho Octavo de la STS núm. 154/2016, de 29 de febrero.

18 Ibid.

19 En la propia Exposición de Motivos de la Ley Orgánica 1/2015 se habla de que se trata de una mera mejora técnica «con la finalidad de delimitar adecuadamente el contenido del «debido control» cuyo quebrantamiento permite fundamentar su responsabilidad penal».

${ }_{20}$ Fundamento de Derecho Octavo de la STS núm. 154/2016, de 29 de febrero.

21 Ibid. 
la responsabilidad penal de las personas jurídicas. Esta idea conectaría con el planteamiento de GómEZ-JARA DíEz para quien los estándares internacionales de Compliance hacen gravitar el centro de cualquier sistema de gestión de Compliance en el establecimiento de una cultura de Complian$\mathrm{ce}^{22}$. Sin embargo, no podemos compartir este posicionamiento puesto que, posteriormente, la sentencia identifica la ausencia de herramientas idóneas y eficaces con el núcleo típico de la responsabilidad penal de las personas jurídicas, complementario de la comisión del ilícito de la persona física, no así la ausencia de una cultura de respeto al derecho.

Esta es la postura mantenida por otros autores como VILLEGAS GARCía quien apunta que, para la sentencia del Pleno de la Sala de lo Penal, la mera constatación de los presupuestos - comisión de un delito por el administrador de una persona jurídica en beneficio de la misma-, no es suficiente para una condena penal de las entidades acusadas, pues de lo contrario no seríamos respetuosos con el derecho a la presunción de inocencia ${ }^{23}$.

Y es que la sentencia expone que, constatada la comisión de un delito por parte de la persona física integrante de la organización, el sistema de responsabilidad penal de la persona jurídica se basa «en la exigencia del establecimiento y correcta aplicación de medidas de control eficaces que prevengan e intenten evitar, en lo posible, la comisión de infracciones delictivas por quienes integran la organización ${ }^{24}$.

Esta autora afirma que «el análisis, pues de una responsabilidad propia de la persona jurídica, manifestada en la existencia o no de instrumentos adecuados y eficaces de prevención del delito, es esencial para concluir su condena» ${ }^{25}$.

Una parte de la doctrina ha identificado como fundamento de la responsabilidad penal de las personas jurídicas una culpabilidad por defecto de la organización ${ }^{26}$. Posición, para este sector doctrinal, lógica a tenor de lo establecido en la exposición de motivos de la Ley Orgánica 1/2015 que llega a afirmar «la finalidad de delimitar adecuadamente el contenido del debido control, cuyo quebrantamiento permite fundamentar su responsabilidad penal». Y en este sentido se expresa BaCigaluPo SAGgeSE cuando

22 Gómez-Jara DíEz, C. El pleno jurisdiccional del Tribunal Supremo sobre responsabilidad penal de las personas jurídicas: fundamentos, voces discrepantes y propuesta reconciliadora. Op. cit., p. 7.

${ }^{23}$ Villegas García, M.A. Hacia un modelo de autorresponsabilidad de las personas jurídicas. La STS (Pleno de Sala de lo Penal) 154/2016, de 29 de febrero. Op. cit., p. 3.

${ }_{24}$ Fundamento de Derecho Octavo de la primera sentencia contenida en la STS núm. 154/2016, de 29 de febrero.

25 Villegas García, M.A. Hacia un modelo de autorresponsabilidad de las personas jurídicas. La STS (Pleno de Sala de lo Penal) 154/2016, de 29 de febrero. Op. cit., p. 4.

26 En este sentido véase Zugaldía EsPinar, J.M. La responsabilidad criminal de las personas jurídicas, de los entes sin personalidad y de sus directivos. Op. cit., pp. 76 y ss. También JAÉN VALLEJO, M. La responsabilidad penal de las personas jurídicas. En Revista Canaria de Ciencias Penales. Núm. 1/1998, p. 69. 
argumenta que la existencia de un déficit o defecto de organización «no es sólo un requisito de la responsabilidad por la infracción del deber de vigilancia de los administradores sobre sus subordinados sino el presupuesto general que legitima la aplicación de una pena a una persona jurídica» ${ }^{27} \mathrm{y}$ que, en consecuencia «la existencia de un déficit o defecto de organización debe ser el presupuesto de punibilidad de las personas jurídicas» ${ }^{28}$.

Por otra parte, para la Sala de lo Penal la naturaleza de la exención basada «en la prueba de la existencia de herramientas de control idóneas y eficaces, cuya ausencia, integraría por el contrario el núcleo típico de la responsabilidad penal de las personas jurídicas, complementario de la comisión del ilícito por la persona física» sería discutible. En este sentido, esta posición contrasta con lo argumentado por la fiscalía en la Circular ${ }^{29}$. Y es que la Sala rechaza este planteamiento del Ministerio Público, puesto que hay que tener en cuenta que «una excusa absolutoria ha de partir, por su propia esencia, de la previa afirmación de la existencia de la responsabilidad, cuya punición se excluye, mientras que, según lo expuesto, la presencia de adecuados mecanismos de control lo que supone es la inexistencia misma de la infracción» ${ }^{30}$.

FeIJóo SÁNCHEz también rechaza esta interpretación de la eximente, en que la existencia de modelos de organización y gestión eficaces suponen una excusa absolutoria vinculada a la punibilidad ${ }^{31}$. Y es que, rescatando, el argumento utilizado en la sentencia, hay que considerar esta afirmación de la circular como «discutible si tenemos en cuenta que una «excusa absolutoria» ha de partir, por su propia esencia, en la previa afirmación de la existencia de la responsabilidad, cuya punición se excluye, mientras que a nuestro juicio la presencia de adecuados mecanismos de control es lo que supone es la inexistencia misma de la infracción».

En definitiva, se inclina esta sentencia a favor de entender el actual sistema como de autorresponsabilidad de las personas jurídicas. Los argumentos que encuentra la Sala son:

- Lo contenido en el propio preámbulo de la LO 1/2015 32 .

27 Vid. Bacigalupo Saggese, S. El modelo de imputación de la responsabilidad penal de los entes colectivos. En: MARÍN DE EsPinosa CEBAllos (coord.) y ZugaLdía EsPINAR (coord.). Aspectos prácticos de la Responsabilidad Criminal de las Personas Jurídicas. Cizur Menor: Aranzadi, 2013, pp. 83- 84.

${ }_{28} \mathrm{Ibid}$., con cita de TiedemanN, de Zugaldía, y de su propia obra sobre La responsabilidad penal de las personas jurídicas. Op cit., pp. 398 y ss.

${ }_{29}$ Circular de la Fiscalía General del Estado 1/2016, p. 56. Argumenta el Ministerio Público que la exención de responsabilidad penal habría de situarse más bien en las proximidades de una excusa absolutoria vinculada a la punibilidad.

${ }^{30}$ Fundamento de Derecho Octavo de la STS núm. 154/2016, de 29 de febrero.

31 Feisóo Sánchez, B. El delito corporativo en el Código Penal Español. Op. cit., p. 97.

32 Recogido así en el Fundamento de Derecho Octavo de la STS núm. 154/2016, de 29 de febrero. 
- Se descarta, también, el modelo vicarial —amparado por la Fiscalía General del Estado- por contradecir este sistema los principios del derecho penal, que también deben estar vigentes para el supuesto de la responsabilidad penal de las personas jurídicas ${ }^{33}$. El principal argumento que utiliza la Sala es que, un modelo de responsabilidad vicarial —en la que la entidad sería responsable penalmente porque lo es la persona física, sin ulteriores análisis sobre su propia culpabilidad - supondría que, para las personas jurídicas, no regirían principios básicos de nuestro sistema de enjuiciamiento penal tales como la exclusión de la responsabilidad objetiva o automática y la no responsabilidad por el hecho ajeno ${ }^{34}$. Y es que, a juicio del Tribunal, constituye un principio fundamental el principio de culpabilidad, recogido del artículo 5 del Código Penal ${ }^{35}$.

- Lo establecido en el artículo 31 ter CP, que permite castigar a la entidad aún sin haber podido concretar o determinar la persona física que cometió el hecho delictivo por la que tendría que responder, ni procesarla, ni condenarla y que, por otra, además, excluye de forma expresa que las circunstancias que afecten a la culpabilidad de dicho individuo puedan incidir en la pena aplicable a la colectiva ${ }^{36}$.

\subsection{El régimen de responsabilidad de las personas jurídicas: requisitos y delito corporativo}

En primer lugar, hay que partir de la idea de que la sentencia, inicialmente, formula dos premisas iniciales, necesarias para poder imputar la responsabilidad penal a las personas jurídicas:

- Previa constatación de la comisión en el seno de la empresa de un delito por parte de una persona física que se adecue a un tipo penal de los que admiten responsabilidad penal de las personas jurídicas, cometido por un directivo o subordinado.

33 En este sentido se pronuncia Carretero Sánchez, S. El papel de los Principios Generales del Derecho en la responsabilidad penal de las personas jurídicas. En Diario la Ley, núm. 8751, Sección Doctrina, 28 de abril de 2016, p. 2. Este autor afirma, en relación con esta cuestión, que «la responsabilidad jurídico penal de las personas jurídicas se debe plantear siempre con el respeto que sustenta el mayor principio del Derecho Penal, el de la culpabilidad». Expone, asimismo, que «las bases ideológicas del Derecho, los principios generales, no pueden ser forzadas en la nueva doctrina. La contradicción y defensa existirá en todo proceso, la tutela judicial efectiva, la presunción de inocencia, el juez predeterminado (...) amparan a la persona jurídica de igual modo que la física, si conlleva obligaciones la nueva regulación mantiene los derechos como es normal».

34 Fundamento de Derecho Octavo de la primera sentencia contenida en la STS núm. 154/2016, de 29 de febrero.

35 Recordemos «No hay pena sin dolo o imprudencia».

36 Galán MuÑoz, A. Fundamentos y límites de la responsabilidad penal de las personas jurídicas tras la reforma de la LO 1/2015. Valencia: Tirant Lo Blanch, 2017, p. 89. 
Y en este caso de los hechos probados de la sentencia, se aprecia la constatación de esta circunstancia.

- Determinar, si existen o no medidas de control eficaces dentro de la persona por quienes integran la organización, que prevengan e intenten evitar, en la medida de lo posible, que se cometan acciones delictuales en el seno de la misma. Es decir, la responsabilidad se establece analizando si el delito ha sido posible o facilitado por la ausencia de una cultura de respeto al Derecho, manifestada en formas concretas de vigilancia y control del comportamiento de sus directivos y subordinados, tendentes a la evitación de la comisión delictiva.

Y en este sentido, también, el Alto Tribunal considera que la falta de medida alguna de prevención delictiva por parte de las entidades enjuiciadas fundamentaba que se les condenase por los delitos de tráfico de drogas cometidos.

En segundo lugar, el Tribunal también realiza varias consideraciones sobre los elementos o requisitos que configuran la base para la atribución de la responsabilidad penal a la persona jurídica.

En este sentido, lo básico es la comisión de un delito individual por una persona física siempre que se cumplan los requisitos contenidos en el Código Penal, esto es:

- La actuación en nombre o por cuenta de la sociedad en el ejercicio de actividades sociales.

En cuyo caso se cumplía en la sentencia, puesto que de conformidad con el apartado primero del art. 31 bis CP, algunas personas físicas contempladas en dicho apartado habían cometido delitos - en este caso, un delito contra la salud pública-.

\section{- El beneficio directo o indirecto.}

Tras la reforma operada en el Código Penal en el año 2015 en la que se sustituyó el concepto de "provecho" por el de beneficio directo o indirecto, el TS ha señalado que dicho término hace alusión a «cualquier clase de ventaja, incluso de simple expectativa o referida a aspectos tales como la mejora de la posición respecto de otros competidores, etc., provechosa para el lucro o para la mera subsistencia de la persona jurídica en cuyo seno el delito de representante, administrador o subordinado jerárquico, se comete» ${ }^{37}$.

37 Fundamento de Derecho Decimotercero de la STS núm. 154/2016, de 29 de febrero. 
La doctrina ha interpretado que solo quedarían excluidas aquellas conductas a través de las cuales la persona física busca su exclusivo y propio beneficio o de un tercero, y que resulten inidóneas para reportar a la entidad beneficios. El determinar o no de la acción, y por ende, su carácter beneficioso debe hacerse desde una perspectiva objetiva e hipotéticamente razonable ${ }^{38}$.

En relación con este elemento, la posición del Tribunal Supremo coincidiría, en lo esencial con la mantenida por la Fiscalía General del Estado en su Circular. Por ello no podemos más que mostrarnos de acuerdo cuando el Ministerio Público señala que esto permite «extender la responsabilidad de la persona jurídica a aquellas entidades cuyo objeto social no persigue intereses estrictamente económicos, así como incluir, ya claramente, los beneficios obtenidos a través de un tercero interpuesto, los consistentes en un ahorro de costes y, en general, todo tipo de beneficios estratégicos, intangibles o reputacionales» ${ }^{39}$, puesto que no encontramos un argumento razonable para sostener lo contrario.

Esta posición del Tribunal Supremo, estaría en concordancia con el parecer de NiETo MARTíN ${ }^{40}$ para quien, también, "hay que prevenir conductas que no suponen «un beneficio» para la persona jurídica, bien porque se lleven a cabo por entes que no buscan beneficio (partidos políticos, sindicatos, iglesias); bien porque lo que se intenta es proteger bienes jurídicos colectivos (prevención de riesgos laborales, bases de datos personales, y de la seguridad del tráfico jurídico frente a las falsedades contables); bien porque el delito no tiene carácter económico (los acosos sexuales en la empresa), bien porque se trata de delitos imprudentes (en los que normalmente no cabe ánimo de lucro)».

En definitiva, este beneficio directo e indirecto es cualquier expectativa provechosa a favor de la entidad, entendido en el mismo sentido que la Sentencia y la Circular.

En el supuesto de hecho se cumple este requisito como expresa la sentencia cuando afirma que "como en el caso que nos ocupa, las ganancias cuantiosas que obtienen los autores del ilícito contra la salud pública no es que favorezcan la subsistencia de la entidad sino que justificarían su propia existencia si, como se dice, se trata de una mera empresa "pantalla» constituida con el designio de

38 Rodríguez Almirón, F.J. La responsabilidad de las personas jurídicas a raíz de la jurisprudencia reciente de Tribunal Supremo. Op. cit., pp. 8-9.

39 Circular de la Fiscalía General del Estado 1/2016, pp. 58-59.

40 Citado por Zugaldía Espinar, J.M. La responsabilidad criminal de las personas jurídicas en el derecho penal español (análisis de la cuestión tras la reforma operada por la LO 1/2015, de 30 de marzo). Op cit., p. 225. 
servir de instrumento para la comisión del delito como su única finalidad, hay que concluir que se cumple el referido requisito sin posible réplica ${ }^{41}$.

Y termina concluyendo en relación a este extremo: «Una interpretación distinta a la expuesta conduciría a la práctica imposibilidad de aplicación del régimen de responsabilidad penal de la persona jurídica, con el incumplimiento que ello pudiera suponer respecto de las finalidades preventivas del sistema, en relación con un gran número de figuras delictivas como la presente, en la que en muchas ocasiones podrá resultar difícil imaginar la obtención de una ventaja directa para aquel ente que desarrolla una actividad, especialmente si fuera ilícita, como consecuencia de la comisión de un ilícito contra la salud pública» ${ }^{42}$.

- Por último, el incumplimiento grave de los deberes de supervisión, vigilancia y control, que la sentencia justifica también para proceder a la condena de las sociedades.

En tercer lugar, del contenido de esta sentencia, podemos ir deduciendo la existencia de un delito corporativo.

Se parte del hecho de que, si se exige un hecho propio para generar responsabilidad penal de las personas físicas, también se ha de hacer lo propio para el caso de las personas jurídicas.

No obstante, en la sentencia pudiera llegar a entenderse que el tipo objetivo de la responsabilidad penal de las personas jurídicas viene constituido por la cultura de cumplimiento de la persona jurídica. Sin embargo, tal y como advierte cierto sector doctrinal ${ }^{43}$, no resulta evidente que la sentencia mayoritaria considere la ausencia de una cultura de respeto al Derecho como un elemento del tipo penal del delito corporativo. Lo que en la sentencia se dice es que «la relevancia penal de la conducta de la persona jurídica (el actuar) ha de establecerse a partir del análisis acerca de si el delito cometido por la persona jurídica en el seno de aquella ha sido posible o facilitado, por la ausencia de una cultura de respeto al Derecho, que habría de manifestarse en formas concretas de vigilancia y control del comportamiento de sus directivos y subordinados jerárquicos, tendentes a la evitación de la comisión de los delitos específicamente señalados en el Libro II del Código Penal».

Apunta FeIJóo SÁnchez que pareciera que la idea del Tribunal Supremo en esta sentencia fuese la de construir la responsabilidad propia de las empresas partiendo de que el delito corporativo es una figura delic-

41 Fundamento de Derecho Decimotercero de la STS núm. 154/2016, de 29 de febrero.

42 Fundamento Decimotercero de la STS núm. 154/2016, de 29 de febrero.

43 Agudo Fernández, E; JaÉn Vallejo, M; Perrino Pérez, A.L. Capítulo IV. La responsabilidad penal de las personas jurídicas en la jurisprudencia. Op. cit., p. 167. 
tiva específicamente en el art. 31 bis «es decir, como si fuese un crimen culpae de la corporación consistente en la ausencia de mecanismos de control» ${ }^{44}$.

Por último, es destacable que el Pleno del Tribunal Supremo también acoge la doctrina de la inimputabilidad de las sociedades pantalla. En este sentido se llega a afirmar que:

«De nuevo se declara probado en el «factum» de la recurrida que estamos ante una «sociedad pantalla», o meramente instrumental, lo que bastaría para la declaración de su responsabilidad penal, de acuerdo con las previsiones al respecto de nuestro Legislador, y la correcta aplicación de tales penas o, en su caso, con mayor corrección su tratamiento como «inimputable» y ajeno por ello al régimen de responsabilidad penal de las personas jurídicas, al que alude la ya citada Circular de la Fiscalía General del Estado 1/2016. Con la consecuencia por supuesto de su disolución ${ }^{45}$.

Para el Tribunal, la sociedad meramente instrumental o pantalla, creada exclusivamente para servir de instrumento en la comisión del delito de la persona física, ha de ser considerada al margen del régimen de responsabilidad respecto de ella, acogiendo así la tesis de la Fiscalía en su Circular 1/2016.

\subsection{El problema de la carga de la prueba en la sentencia mayoritaria}

Consecuencia de lo anterior, se origina un problema de indubitada trascendencia práctica forense como es la carga de la prueba, con respecto a la que, en una interpretación coherente con lo señalado a lo largo de la sentencia, el Alto Tribunal indica que «la acusación se ha de ver lógicamente obligada, para sentar los requisitos fácticos necesarios en orden a calificar a la persona jurídica como responsable, a afirmar la inexistencia de tales controles» ${ }^{46}$.

Sin embargo, esta interpretación tiene la ventaja de que, si la acusación no es capaz de demostrar la ausencia de medidas eficaces de prevención de delitos, no se llegue a abrir la causa penal o, de abrirse, que ésta pueda quedar sobreseída en un estadio muy temprano de las diligencias de investigación, por no ser el hecho penalmente relevante ${ }^{47}$.

${ }^{44}$ Feijóo Sánchez, B. El delito corporativo en el Código Penal Español. Op. cit., p. 101.

45 Fundamento de Derecho Decimotercero de la STS núm. 154/2016, de 29 de febrero.

46 Fundamento de Derecho Octavo de la STS núm. 154/2016, de 29 de febrero.

47 Del Rosal Blasco, B. Sobre los elementos estructurales de la responsabilidad penal de las personas jurídicas: reflexiones sobre las SSTS 154/2016 Y 221/2016 y sobre la circular núm. 1/2016 de la Fiscalía General del Estado. Op. cit., p. 3. 


\subsection{La emisión de un Voto Particular}

La exposición relatada con anterioridad no es unánime en todas las cuestiones analizadas por la totalidad de magistrados componentes del pleno. Así las cosas, 7 de los 15 magistrados — los excelentísimos señores D. Cándido Conde-Pumpido Tourón, D, Miguel Colmenero Menéndez de Luarca, D. Luciano Varela Castro, D. Alberto Jorge Barreiro, D. Antonio del Moral García, D. Andrés Palomo de Arco y D. Joaquín Giménez García, emiten un Voto Particular formulado por D. Cándido-Pumpido Tourón, en la que discrepan de los restantes magistrados en una serie de puntos.

En primer lugar, los firmantes llegan a manifestar que no cuestionan «que el fundamento último de la responsabilidad penal de las personas jurídicas se encuentre en la ausencia de medidas eficaces de prevención y control de su funcionamiento interno como el fundamento último de la sanción penal del homicidio se encuentra en el respeto a la vida».

En relación con la naturaleza de la exención, el Voto Particular parte de que la exención, contenida en los párrafos segundo y cuarto del art. 31 bis, es coherente con el fundamento último de la responsabilidad penal de las personas jurídicas, de tal manera que la existencia de un modelo de organización y gestión eficaz «debe producir como consecuencia la exclusión de su responsabilidad penal» ${ }^{48}$.

Tal y como señala la doctrina ${ }^{49}$ es verdaderamente interesante destacar que el Voto Particular por primera vez habla de los elementos que integran el tipo objetivo que no parece ser el tipo objetivo del delito cometido por la persona física.

Esto, unido al reconocimiento de una culpabilidad propia de la persona jurídica, permitiría afirmar que la persona jurídica comete un delito propio y distinto del cometido por las personas físicas (contradiciendo así la tesis de la Fiscalía General del Estado sobre la responsabilidad vicarial o por transferencia). E igualmente permitiría afirmar que la persona jurídica es «autora» de su propio delito, término éste empleado en la propia sentencia para referirse a la persona jurídica. Si ambos delitos —el de la persona física y la persona jurídica— son distintos y difieren en

48 Vid. Feisóo SÁnchez, B. El delito corporativo en el Código Penal Español. Op.cit., pp. 97-98. Para este autor, el Voto Particular entiende que el legislador ha atribuido expresamente a los modelos de organización y gestión la función de exención o, en su caso, atenuación de la responsabilidad penal. De esta manera los magistrados de este Voto Particular se colocan en una posición intermedia entre la Sentencia Mayoritaria y la Circular de la Fiscalía General del Estado 1/2016, defendiendo un modelo vicarial con posibilidad de exención autónoma de responsabilidad.

49 Agudo Fernández, E; Jaén Vallejo, M; Perrino Pérez, A.L. Capítulo IV. La responsabilidad penal de las personas jurídicas en la jurisprudencia. Op. cit., p. 163. 
su estructura típica, podría pensarse que la estructura del delito cometido por la persona jurídica será siempre la misma con absoluta independencia de la concreta estructura del delito de la parte especial cometida por la persona física ${ }^{50}$.

En relación con la visión del tipo objetivo, los firmantes del Voto Particular no comparten la sentencia mayoritaria en cuanto a que la inexistencia o defectuosa configuración de medidas preventivas en la persona jurídica pudiesen ser consideradas como el núcleo de la tipicidad del delito. Dicha responsabilidad de las personas jurídicas se sustentaría, en realidad en lo establecido en las dos primeras letras del primer apartado del art. 31 bis CP, sin que ello, sin embargo, supusiese que se las responsabilizara automática y objetivamente por las actuaciones delictiva realizadas por las personas físicas allí mencionadas dado que dichas entidades responderían por el hecho de que habrían permitido a sus superiores o dirigentes cometer delitos ${ }^{51}$.

Además, también señalan que la exigencia de un elemento como la denominada «ausencia de cultura de respeto al derecho» entendida "como fuente de inspiración de la actuación de su estructura organizativa e independiente de la de cada una de las personas físicas que la integran» es poco segura y difícilmente compatible con el requerimiento de certeza propio de la tipicidad penal.

Respecto de la culpabilidad ${ }^{\mathbf{5 2}}$ señala que la persona jurídica es responsable penalmente de los delitos cometidos por las personas a las que se refiere el artículo 31 bis:

«(...) porque es culpable (en la escasa medida en que este concepto puede ser aplicado a una persona jurídica, que no deja de constituir una ficción). Pero esta culpabilidad la infiere el Legislador, en el apartado a) del art. 31 bis CP que es el aquí aplicado, del hecho de permitir que sus representantes cometan un acto delictivo, en nombre y por cuenta de la sociedad y en su beneficio. Y se fundamenta en los principios generales de la "culpa in eligendo" y la "culpa in vigilando", o incluso si se quiere profundizar más, de culpa "in constituendo" y la culpa "in instruendo" ".

${ }^{50}$ Conclusión a la que llegan Agudo Fernández, E; JaÉn Vallejo, M; Perrino Pérez, A.L. Capítulo IV. La responsabilidad penal de las personas jurídicas en la jurisprudencia. Op. cit., p. 163.

51 Galán Muñoz, A. Fundamentos y límites de la responsabilidad penal de las personas jurídicas tras la reforma de la LO 1/2015. Op. cit., p. 91.

52 Del Rosal Blasco, B. Sobre los elementos estructurales de la responsabilidad penal de las personas jurídicas: reflexiones sobre las SSTS 154/2016 Y 221/2016 y sobre la Circular núm. 1/2016 de la Fiscalía General del Estado. Op. cit., p. 5. Ese autor pone de manifiesto que la posición de los magistrados discrepantes se aproxima más al planteamiento tradicional de TIEDEMANN para quien, respecto de las personas jurídicas, se ha de mantener la exigencia de culpabilidad y ésta ha de construirse por referencia al defecto de organización. 
Además, tal y como pone de manifiesto un sector de la doctrina ${ }^{53}$, si se admite la hipótesis de la sentencia mayoritaria, es decir, que la ausencia de una cultura de respeto al Derecho es un elemento del tipo objetivo, entonces la confirmación de la condena de la persona jurídica en el supuesto casacional resuelto por la sentencia habría exigido que en el relato de hechos probados se incluyera tal elemento como hecho acreditado. Sin embargo, en el relato de hechos probados de la sentencia nada se dice al respecto.

Con relación a este extremo, es cierto que todos los elementos del tipo penal por el que se condena deben estar probados y es igualmente evidente que todos los hechos probados deben describirse en la sentencia. Siendo esto así, si la sentencia no considera probado un elemento esencial del tipo, la consecuencia sólo puede ser la absolución.

La consecuencia por tanto es que a la acusación sólo le corresponde probar la concurrencia de los elementos recogidos en los apartados a) y b) del art. 31 bis, núm. 1, pero no le corresponde probar «en cada supuesto enjuiciado un presupuesto de tipicidad tan evanescente y negativo como demostrar que el delito ha sido facilitado por la ausencia de una cultura de respeto al Derecho en el seno de la persona jurídica afectada».

Y esto es así porque, tal y como llama la atención Gómez-JARA DíEZ sobre este aspecto, «ese resultado no sólo constituye una suerte de probatio diabólica al tener que probar un elemento negativo y ser de más fácil prueba por la defensa, sino que, además, no se compadece con la larga tradición jurisprudencial del Alto Tribunal que asigna la carga probatoria de las eximentes a quien las aduce» ${ }^{54}$.

Y, por tanto, a la empresa le corresponde probar la concurrencia de los instrumentos adecuados y eficaces de prevención del delito. Sentencian estos magistrados que no aprecian «razón alguna que justifique alterar las reglas probatorias aplicables con carácter general para la estimación de circunstancias eximentes, imponiendo que en todo caso corresponda a la acusación la acreditación del hecho negativo de no concurrencia», mostrando su clara discrepancia con el sentir mayoritario de la Sala del Tribunal Supremo puesto que consideran «que no procede constituir a las personas jurídicas en un modelo privilegiado de excepción en materia probatoria, imponiendo a la acusación la acreditación de hechos negativos».

53 Agudo Fernández, E; JaÉn Vallejo, M; Perrino Pérez, A.L. Capítulo IV. La responsabilidad penal de las personas jurídicas en la jurisprudencia. Op. cit., p. 169.

${ }_{54}$ Gómez-JARA DíEz, C. El pleno jurisdiccional del Tribunal Supremo sobre responsabilidad penal de las personas jurídicas: fundamentos, voces discrepantes y propuesta reconciliadora. Op. cit., p. 12. 


\subsection{Una primera reflexión de la sentencia. La propuesta de una conciliación entre la sentencia mayoritaria y el Voto Particular}

De lo analizado hasta este momento, resulta evidente el claro distanciamiento existente en algunas cuestiones dentro de la propia Sala del Tribunal Supremo, hasta tal punto que para parte de la doctrina ${ }^{55}$ esta sentencia refleja una clara divergencia de opiniones entre dos grandes posicionamientos con relación a la naturaleza de la responsabilidad penal de las personas jurídicas, o en cuanto a la concreta estructura del delito corporativo.

Parece, en definitiva, como hemos puesto de manifiesto, que, para la sentencia mayoritaria, el tipo objetivo de la responsabilidad penal de la persona jurídica viniese constituido por la cultura de cumplimiento de la persona jurídica - por lo que la carga de la prueba ha de recaer sobre la acusación- mientras que el Voto Particular se posicionaría de una forma completamente opuesta.

A este respecto, un destacado autor, GómEz-JARA DíEZ ${ }^{56}$ ha intentado formular una conciliación de estos dos posicionamientos. Este autor parte de la idea de que «si se añadiera como elemento del tipo la falta de cultura de cumplimiento de legalidad, se estaría vulnerando el principio de taxatividad». En opinión del autor, ello haría que, obligatoriamente, la cultura de cumplimiento no pueda ser considerado un elemento objetivo del tipo. Para solventar este problema distingue entre:

- Medidas de control referidas a los hechos concretos/delito concreto objeto de imputación, puesto que pudiera resultar que, la persona jurídica gozara de medidas de vigilancia y control que, en general, resultan idóneas para "reducir de forma significativa el riesgo de comisión» de delitos de la misma naturaleza que el imputado a la persona jurídica pero que, a la vista de las circunstancias concretas del supuesto enjuiciado, no resultaran idóneas para conjurar el riesgo y considerarlo como riesgo permitido. Para este autor «en este caso le correspondería a la acusación la carga probatoria respecto de la falta de idoneidad de las medidas de control respecto del delito concreto que se imputa a la persona jurídica sobre la base de los hechos concretos objeto de acusación».

55 Galán Muñoz, A. Fundamentos y límites de la responsabilidad penal de las personas jurídicas tras la reforma de la LO 1/2015. Op. cit., p. 92.

${ }^{56}$ Este autor propone lo que él denomina como una "solución integradora». GómEzJARA DíEz, C. El pleno jurisdiccional del Tribunal Supremo sobre responsabilidad penal de las personas jurídicas: fundamentos, voces discrepantes y propuesta reconciliadora. Op. cit., pp. 12-13. 


\section{- Funcionamiento del sistema de gestión de Compliance penal/} modelo organizativo de organización y gestión de delitos. Y es que, el hecho de que las medidas concretas de vigilancia y control para el delito concreto imputado a la persona jurídica no sean idóneas para considerar que se opera en el ámbito del riesgo permitido, no significa que la persona jurídica merezca un reproche culpabilístico, toda vez que pueda mostrar que, en el momento de los hechos, gozaba de una adecuada cultura de cumplimiento de la legalidad y que es merecedora de una exención de responsabilidad penal». En opinión de este autor, para este supuesto «la prueba de la cultura de cumplimiento de la legalidad —incluida la prueba de la idoneidad de las medidas de vigilancia y control genéricas para delitos de la misma naturaleza-corresponde a la defensa»

\section{A vueltas con la resposabilidad penal de las personas jurídicas. La sentencia del Tribunal Supremo núm. 221/2016, de 16 de marzo de 2016 (Ponente: Excmo. Sr. Manuel Marchena Gómez)}

En esta nueva sentencia, muy cercana en el tiempo a la anterior, el Alto Tribunal vuelve a remarcar los principios irrenunciables que informan el Derecho penal en esta materia al afirmar que «la responsabilidad de las personas jurídicas sólo puede declararse después de un proceso con todas las garantías» y que la imposición de cualquiera de las penas «solo puede ser el desenlace de una actividad jurisdiccional sometida a los principios y garantías que legitiman la actuación del ius puniendi ${ }^{57}$.

Además, la sentencia insiste en reconocer que el defecto estructural en los modelos de gestión, vigilancia y supervisión constituye el fundamento de la responsabilidad del delito corporativo ${ }^{58}$.

Como reseñable novedad, estamos ante una resolución en la que se reconoce, ya de un modo expreso, la existencia de un delito corporativo referido a las personas jurídicas.

Ahondando en esta cuestión, la Sala llega a afirmar que «la responsabilidad de la persona jurídica ha de hacerse descansar en un delito corporativo construido a partir de la comisión de un previo delito por la persona física, pero que exige algo más: la proclamación de un hecho

57 Se enjuicia un supuesto de estafa en el que, un representante de una empresa inmobiliaria, haciendo una función de intermediación, cobra dos comisiones por la misma compraventa, primero al vendedor y después al comprador, ocultando deliberadamente el sobrepago.

58 Fundamento de Derecho Quinto de la STS núm. 221/2016, de 16 de marzo. 
propio con arreglo a criterios de imputación diferenciados y adaptados a la especificidad de la persona colectiva» y añade «la Sala no puede identificarse con la tesis de que en el sistema español pueda hablarse de una responsabilidad penal de las personas jurídicas, pero no de un delito de las personas jurídicas. No hay responsabilidad penal sin delito precedente. Lo contrario abriría una peligrosísima vía con efectos irreversibles en los fundamentos mismos del sistema penal» ${ }^{59}$.

Por otra parte, en concordancia con el anterior pronunciamiento, la Sala no admite fórmulas de responsabilidad objetiva «en las que el hecho de uno se transfiera a la responsabilidad del otro, aunque ese otro sea un ente ficticio sometido, hasta hace bien poco, a otras formas de responsabilidad». La pena impuesta a la persona jurídica sólo puede fundamentarse en la previa declaración como probado de un hecho delictivo propio ${ }^{60}$.

En relación con los requisitos, que constituyen la base para exigir responsabilidad a la persona jurídica, esta sentencia hace diversas consideraciones.

En primer lugar, el hecho sobre el que ha de hacerse descansar la imputación no podrá prescindir del delito de referencia atribuido a la persona física, pero "habrá de centrarse en su averiguación desde una perspectiva estructural» indagando «sobre aquellos elementos organizativos-estructurales que han posibilitado un déficit de los mecanismos de control y gestión, con influencia decisiva en la relajación de los sistemas preventivos llamados a evitar la criminalidad en la empresa ${ }^{61}$.

En este mismo sentido, afirma que la presunción de inocencia impide mantener «la tesis de que, una vez acreditado el hecho de conexión, esto es, el particular delito cometido por la persona física existiría una presunción iuris tantum de que ha existido un defecto organizativo».

En segundo lugar. en esta sentencia, el Tribunal sí que hace un mayor hincapié en otro de los requisitos que configuran la base para la atribución de la responsabilidad penal a la persona jurídica: la necesaria acreditación del incumplimiento grave de los deberes de supervisión, vigilancia y control de su actividad por parte de la empresa, por un defecto estructural en los mecanismos de prevención exigibles.

Afirma que «sea cual sea el criterio doctrinal mediante el que pretende explicarse la responsabilidad de los entes colectivos, ésta no puede afirmarse a partir de la simple acreditación del hecho delictivo atribuido a la persona física, siendo necesario que la persona jurídica haya incum-

\footnotetext{
59 Ibid.

${ }^{60}$ Fundamento de Derecho Quinto de la STS núm. 221/2016, de 16 de marzo.

61 Ibid.
} 
plido gravemente los deberes de supervisión, vigilancia y control de su actividad, atendidas las circunstancias del caso».

Ahondando en esta idea, los magistrados consideran que los incumplimientos menos graves o leves de los deberes de supervisión, vigilancia y control de su actividad quedan extramuros de la responsabilidad penal de los entes colectivos ${ }^{62}$.

Además, señala que «la vigencia del derecho a la presunción de inocencia impone que el Fiscal no se considere exento de la necesidad de acreditar la concurrencia de un incumplimiento grave de los deberes de supervisión».

\section{Una resolución singular: la sentencia del Tribunal Supremo núm. 516/2016, de 13 de junio de 2016 (Ponente: Excmo. Sr. Andrés Martínez Arrieta)}

En esta sentencia se enjuicia un delito contra los recursos naturales y el medio ambiente. El supuesto de hecho es un administrador de una empresa que gestionaba una mina que estaba siendo explotada, a pesar de que la normativa administrativa impedía realizar dicha actividad y, a pesar, de que generaba unos residuos que afectaban al entorno y a un arroyo cercano.

El Tribunal vuelve a hacer hincapié para ratificar que el artículo 31 bis $\mathrm{CP}$ «señala los presupuestos que han de concurrir para la declaración de la persona jurídica como autora del delito, este es, un delito cometido por persona física - representantes legales o empleados- en nombre o por cuenta de una persona jurídica o en el ejercicio de las actividades sociales por cuenta o en beneficio directo o inmediato de la personas jurídica, y que por ésta no han adoptado las medidas de organización y gestión necesarias, que incluyan medidas de vigilancia y control de los posibles resultados típicos que el ejercicio de su actividad de la persona jurídica pueda realizar» ${ }^{63}$.

No obstante, tal y como ha señalado la doctrina, el Tribunal atribuyó el sistema de la teoría del delito de la persona jurídica del Código Penal al modelo de responsabilidad vicarial ${ }^{64}$. En este sentido, la sentencia llega a señalar que «en el diseño de esta imputación a título de autor del delito de la persona jurídica, el legislador ha optado por un sistema vicarial, siendo independiente la responsabilidad penal de la persona física y de la jurídica» ${ }^{65}$.

62 Ibid.

${ }^{63}$ Fundamento de Derecho Primero de la STS núm. 616/2016, de 13 de junio.

${ }^{64}$ Galán Muñoz, A. Fundamentos y límites de la responsabilidad penal de las personas jurídicas tras la reforma de la LO 1/2015. Op cit., p. 96.

${ }_{65}$ Fundamento de Derecho Primero de la STS núm. 616/2016, de 13 de junio. 
Sin embargo, ello fue corregido en el posterior Auto de aclaración y corrección de errores, de $\mathbf{2 8}$ de junio de 2016, en el que se sustituyó la referencia al sistema vicarial de responsabilidad por la referencia al sistema de responsabilidad individual de la propia persona jurídica, esto es, al de autorresponsabilidad de la persona jurídica ${ }^{66}$.

Como se puede observar, consideramos esta rectificación coherente con lo argumentado en la propia sentencia puesto que en ella se reconoce que en el tiempo de la comisión de los hechos —de junio de 1997 a febrero de 2009- no existía un precepto en el que se reconociese la responsabilidad penal de las personas jurídicas y «consecuentemente, tampoco esa responsabilidad formó parte del proceso. Además, aún en el supuesto de que, salvadas las exigencias derivadas del principio de legalidad y del acusatorio, se hubiera ejercido la acción penal contra la persona jurídica, la redacción del precepto no excluye la de la persona física que la representa si concurren en él los elementos de la autoría precisos para la imputación y la subsunción de su conducta en la norma» ${ }^{67}$. De este fragmento, podemos interpretar que si a una persona jurídica no se le puede condenar sin haber sido acusada — aunque si haya sido acusada la persona física que actuó en su seno- no podemos afirmar el reconocimiento de un sistema vicarial.

\section{Los pronunciamientos posteriores del Tribunal Supremo en torno a esta cuestión. La reafirmación de su jurisprudencia}

Con posterioridad a las resoluciones comentadas en el punto anterior, el Tribunal Supremo ha tenido la oportunidad de pronunciarse en varias ocasiones en torno a la responsabilidad penal de las personas jurídicas, manteniéndose en lo esencial con lo afirmado con anterioridad. A continuación, pasamos a desarrollar, sucintamente, algunos de estos fallos.

En primer lugar, la Sentencia del Tribunal Supremo Núm. 827/2016, de 3 de noviembre de 2016 (Ponente: Excmo. Sr. José Ramón Soriano Soriano) en donde, como consecuencia del listado de numerus clausus de los delitos que pueden cometer las personas jurídicas, la sociedad implicada es condenada por un delito de estafa procesal perpetrado por su administrador, pero no así por un delito de falsedad documental tam-

${ }^{66}$ Literalmente se dice en el mencionado auto «se indica erróneamente una opción del legislador por un sistema vicarial cuando conforme se deduce del resto de la fundamentación, la opción es por un sistema de auto-responsabilidad. Así resulta de la fundamentación al afirmar que ambas, personas físicas y jurídica, responde por su propia responsabilidad en términos que definen, respectivamente, los art. 28 y 31 bis $\mathrm{CP}$ ».

${ }^{67}$ Fundamento de Derecho Primero de la STS núm. 616/2016, de 13 de junio, 
bién atribuido a la persona física. Podemos destacar el pronunciamiento que realiza el Tribunal cuando afirma que «el principio acusatorio impide la condena de una persona sin haber sido formalmente acusada ${ }^{68}$, del que, de nuevo inferimos, la exclusión del modelo vicarial, puesto que, en base a este principio, una persona jurídica no puede ser condenada sin haber sido acusada.

En segundo lugar, la Sentencia del Tribunal Supremo Núm. 31/2017, de 26 de enero de 2017 (Ponente: Excmo. Sr. Miguel Colmenero Menéndez de Luarca) en la que, aunque finalmente, no se llega a declarar la responsabilidad penal de las persona jurídica, sí que podemos volver a incidir en la idea de la importancia que para el Alto Tribunal tiene el principio acusatorio en nuestro derecho penal ${ }^{69}$ y que nos permite, excluir, como hemos tenido ya la ocasión de argumentar, el modelo de responsabilidad vicarial.

En tercer lugar, resulta muy relevante el Auto del Juzgado Central de Instrucción Número 4 de la Audiencia Nacional, de 11 de mayo de 2017 (Ponente: Sr. D. Fernando Andreu Merelles) que ha indicado expresamente en qué debe consistir la labor instructora respecto de las personas jurídicas. Tal y como indica GómEZ-JARA DíEZ ${ }^{70}$ «el Magistrado ha indagado si, más allá de un posible delito individual por parte de un representante de la persona física, ésta, como tal, adolecía de un déficit estructural». Y termina concluyendo «Los Instructores deben valorar las medidas de vigilancia y control de las personas jurídicas de tal forma que si éstas son idóneas no se puede encausar a una persona jurídica al no concurrir indiciariamente un defecto estructural en los mecanismos de prevención y control» ${ }^{71}$.

Más ilustrativas parecen, no obstante, las sentencias posteriores dictadas por este órgano jurisdiccional.

Por un lado, la Sentencia del Tribunal Supremo Núm. 583/2017, de 19 de julio de 2017 (Ponente: Excmo. Sr. Antonio del Moral García) donde, en un supuesto de blanqueo de capitales, el Tribunal indica que la responsabilidad penal de las personas jurídicas se ajusta a las exigencias contenidas en el art. 31 bis ya que " a) Sus administradores y directivos (tanto de hecho como de derecho) (...() actuando en representación de la empresa han llevado a cabo una continuada actividad encajable en el art. $301 \mathrm{CP}$ que es precisamente una de las figuras delictivas en que el legislador prevé la imposición de penas para las

${ }_{68}$ Fundamento de Derecho Segundo de la STS núm. 827/2016, de 3 de noviembre.

69 Fundamento de Derecho Sexto de la STS núm. 31/2017, de 26 de enero.

70 Gómez-Jara Díez, C. Compliance y delito corporativo: a propósito del auto de 11 de mayo de 2017 del juzgado central de instrucción número cuatro (Caso Bankia). En Diario La Ley, núm. 9018, Sección Doctrina, 11 de julio de 2017, p. 8.

71 Ibid., p. 15. 
personas jurídicas (...), b) concurre un innegable provecho o beneficio directo de la sociedad (...) c) y, por fin, está cubierta también la faz negativa de esa atribución de responsabilidad: la persona jurídica carecía de un sistema efectivo de control implemento para anular o, al menos, disminuir eficazmente el riesgo de comisión en el seno de la empresa de ese delito" ${ }^{72}$.

Por otro lado, en la Sentencia del Tribunal Supremo Núm. 668/2017, de 11 de octubre de 2017 (Ponente: Excmo. Sr. Manuel Marchena Gómez), donde se enjuicia un delito ecológico, el Alto Tribunal sigue insistiendo en que «más allá de la rica complejidad que anima el debate dogmático acerca de la responsabilidad penal de las personas jurídicas, la jurisprudencia hasta ahora dictada en esta materia ha proclamado la necesidad, ya se opte por un modelo de responsabilidad por el hecho propio, ya por una fórmula de heterorresponsabilidad de que cualquier pronunciamiento condenatorio de las personas jurídicas habrá de estar basado en los principios irrenunciables que informan el derecho penal» no cabiendo por tanto «una objetivación de este rupturista régimen de responsabilidad criminal de los entes colectivos, construido a espaldas del principio de culpabilidad proclamado en el art. $5 \mathrm{CP} »^{73}$.

Vuelve a afirmarse que «el sistema de responsabilidad de las personas jurídicas se basa, sobre la previa constatación de la comisión del delito por parte de la persona física integrante de la organización como presupuesto inicial de la referida responsabilidad, en la exigencia del establecimiento y correcta aplicación de medidas de control eficaces que prevengan e intenten evitar, en lo posible, la comisión de infracciones delictivas por quienes integran la organización», añadiéndose que, la responsabilidad de los entes colectivos aparece, por tanto, ligada a «la ausencia de una cultura de respeto al Derecho, como fuente de inspiración de la actuación de su estructura organizativa e independiente de la de cada una de las personas físicas que la integran, que habría de manifestarse en alguna clase de formas concretas de vigilancia y control del comportamiento de sus directivos y subordinados jerárquicos ${ }^{74}$.

\section{La concreta estructura del delito corporativo reconocido por el Tribunal Supremo: el debate doctrinal}

Como hemos tenido la oportunidad de comentar, tras las modificaciones en torno a la cuestión de la responsabilidad penal de las personas jurídicas realizadas en nuestro Código Penal - a través de las reformas

72 Fundamento de Vigesimoctavo contenido en la STS núm. 583/2017, de 19 de junio.

73 Fundamento Jurídico Primero de la STS núm. 668/2017, de 11 de octubre.

74 Ibid. 
operadas en 2010 y 2015- y el pronunciamiento que realizó sobre las mismas el Ministerio Fiscal, nos encontrábamos ante la incertidumbre de cuál sería el posicionamiento del Tribunal Supremo con relación al modelo de responsabilidad que debía regir para estos entes colectivos.

Tras el análisis de las resoluciones de este órgano jurisdiccional, el rechazo a un modelo de heterorresponsabilidad o vicarial, parece una cuestión evidente. Pero es que no sólo los argumentos empleados por el Tribunal Supremo en estas resoluciones parecen avalar esta postura, sino que ello se puede deducir del propio tenor literal de la legislación reguladora de esta materia. En primer lugar, porque el propio preámbulo de la Ley Orgánica 1/2015, de 30 de marzo, establece que con esa reforma «se pone fin a las dudas interpretativas que había planteado la anterior regulación, que desde algunos sectores había sido interpretada como un régimen de responsabilidad vicarial». En segundo lugar, porque, en virtud del artículo 31 ter 1, la atribución de la responsabilidad criminal a la persona jurídica se realiza con total independencia de que se identifique a las personas física que ha actuado ostentando los cargos o funciones a los que se refiere el artículo 31 bis, aun en el caso de que la concreta persona física no haya sido individualizada o no haya sido posible dirigir el procedimiento contra ella. Por último, porque, en virtud del artículo 31 ter 2, la culpabilidad de la persona jurídica es independiente de la culpabilidad de la persona física que realizada el «el hecho de conexión».

Pero es que, además, igualmente, del análisis jurisprudencial realizado hasta el momento parece, también, evidente, que el Tribunal Supremo reconoce la existencia de un tipo objetivo propio y de una culpabilidad también propia de la persona jurídica, además de contemplarse una actuación propia de la misma, tal y como ha sido puesto de manifestó por la doctrina ${ }^{75}$. Cabe recordar aquí, en este sentido, la Sentencia del Tribunal Supremo de 16 de marzo de 2016, que es su Fundamento de Derecho Quinto llegaba a sostener que:

«La responsabilidad de la persona jurídica ha de hacerse descansar en un delito corporativo construido a partir de la comisión de un delito previo por la persona física, pero que exige algo más, la proclamación de un hecho propio con arreglo a criterios de imputación diferenciados y adaptados a la especificidad de la persona colectiva. De lo que se trata, en fin, es de aceptar que sólo a partir de una indagación por el Juez Instructor de la efectiva operatividad de los elementos estructurales y organizativos asociados a los modelos de prevención, podrá construirse un sistema respetuoso con el principio de culpabilidad». Se reconocía así: «(...) la concurrencia de un delito corporativo, por un defecto estructural en los mecanismos de prevención exigibles a toda persona jurídica, de forma mucho más precisa, a partir de la reforma de 2015»

75 Agudo Fernández, E; JaÉn Vallejo, M; Perrino Pérez, A.L. Capítulo IV. La responsabilidad penal de las personas jurídicas en la jurisprudencia. Op. cit., p. 163. 
Consecuencia de lo anterior es, como ya hemos tenido la ocasión de señalar, que se produce por tanto un reconocimiento expreso - por parte del Tribunal Supremo- de un delito corporativo que - llega a sostener este órgano jurisdiccional- se encuentra conformado por los «elementos organizativos-estructurales que han posibilitado un déficit de los mecanismos de control y gestión, con influencia decisiva en la relajación de los sistemas preventivos llamados a evitar la criminalidad en la empresa».

Por otro lado, como también se ha puesto de manifiesto, existe una clara discrepancia dentro del propio Tribunal Supremo acerca de cuál ha de ser la concreta construcción dogmática que tiene que tener este delito corporativo. Las sentencias analizadas lo único que muestran es una clara discrepancia entre dos posturas, generándose con ello inseguridad jurídica. Lo único cierto de todo ello es qué cuestiones relativas a los específicos elementos que integran la estructura típica del delito corporativo (tipo objetivo/subjetivo), constituyen aspectos sobre los que el Tribunal habrá de pronunciarse en un futuro, puesto que el estado actual de esta cuestión impide realizar una satisfactoria salida en torno a este extremo.

No obstante, la doctrina sí que se ha ido posicionando acerca de este asunto con el objetivo de proponer un modelo plausible, cómo el existente para el caso de los delitos de las personas físicas.

En este sentido, uno de los más destacados autores que han realizado aportaciones doctrinales acerca de esto ha sido ZugaLdía EsPINAR. Dicho autor ha señalado que, al margen de estos conceptos de acción y culpabilidad propios de la persona física, existen otros exclusivos de la persona jurídica sobre la que es posible construir su responsabilidad criminal, por la que no es éste «un problema ontológico, sino un simple problema de definición ${ }^{76}$. Con respecto a que ha de entenderse por el concepto de capacidad de acción de la persona jurídica y su acción en sí, ZugaLdía ESPINAR ha afirmado que «las acciones de un órgano de una persona jurídica (hecho de referencia) llevada a cabo de acuerdo con determinados criterios normativos de imputación son acciones de la propia persona jurídica» ${ }^{77}$.

76 Zugaldía EsPinar, J.M. La responsabilidad penal de empresas, fundaciones y asociaciones. Op. cit., p. 3. Para este autor el principio «Societas delinquere non potest»constituye la plasmación de lo que él denomina «un burdo error metodológico» porque se parte de la afirmación de que «las personas jurídicas no pueden delinquir porque no son capaces ni de acción, ni de culpabilidad ni de pena, pero porque se parte, a priori, de unos conceptos de acción, de culpabilidad y de pena que se han elaborado (y sirven solamente) para las personas físicas». En este sentido, vid., también, la obra de este autor ZuGALDía ESPINAR, J.M. La responsabilidad criminal de las personas jurídicas, de los entes sin personalidad y de sus directivos. Op. cit., p. 55.

77 Zugaldía Espinar, J. M. La responsabilidad penal de empresas, fundaciones y asociaciones. Op. cit., p. 154. 
Así mismo, autores como Bacigalupo SAgGese ${ }^{78}$ han indicado que «el modelo de imputación debe basarse sobre la existencia de un hecho de conexión y sobre la idea de la culpabilidad por defecto de organización ${ }^{79}$.

Para FeIJóo SÁnCHEZ ${ }^{80}$ el delito corporativo sería la suma de tres presupuestos. En primer lugar, una acción típica y antijurídica de la persona física que tenga una relación funcional con la persona jurídica siempre que de la acción delictiva deriven efectos beneficiosos para la entidad. En segundo lugar, un déficit grave de control, vigilancia y supervisión por parte de terceras personas cuyo cumplimiento hubiera podido evitar el delito con una probabilidad rayana en la certeza. Y, en último lugar, la presencia de un defecto organizativo-estructural relacionado con políticas de cumplimiento de la legalidad —en caso de que se diesen los dos presupuestos anteriores, la responsabilidad penal de la persona jurídica se puede ver en todo caso excluida siempre que se hayan implantado estructuras o un sistema eficaz de cumplimiento de la legalidad en la organización de la que la persona jurídica es titular.

Centrado ya el debate en torno a esta cuestión, se expone, a continuación, cuáles son las principales corrientes doctrinales acerca de la concreta estructura de los diferentes elementos que integran el delito corporativo, que los diferentes autores defienden que se infiere tanto de los pronunciamientos del Tribunal Supremo - en las distintas sentencias que hemos tenido ocasión de examinar- como del propio tenor literal de la ley, y que a continuación exponemos de una manera lacónica.

\section{En primer lugar, sobre la categoría de tipicidad, estas son las prin- cipales posturas existentes:}

- Las que entienden que el artículo 31 bis configura una modalidad de participación delictiva realizada en régimen de comisión por omisión (artículo $11 \mathrm{CP}$ ), siendo la persona jurídica garante de

78 BaCigalupo SAgGeSE, S. El modelo de imputación de la responsabilidad penal de los entes colectivos. Op. cit., p. 83.

79 Esto contrasta con el régimen del artículo $129 \mathrm{CP}$ en el que no es suficiente con la existencia de un hecho de conexión, sino que, para que pueda imponerse alguna de las consecuencias accesorias allí previstas, es necesario que exista un autor responsable del hecho, condenado a una determinada pena, puesto que las consecuencias accesorias lo son de la pena. Estas consecuencias, tal y como señala el mencionado precepto, están previstas «en caso de delitos cometidos en el seno, con la colaboración, a través, o por medio de empresas, organizaciones, grupos o cualquier otra clase de entidades o agrupaciones de personas que, por carecer de personalidad jurídica, no estén comprendidos en el artículo 31 bis». Para una mayor profundidad sobre las penas accesorias aplicables a los entes sin personalidad jurídica Vid. Zugaldía EsPINAR, J. M. La responsabilidad criminal de las personas jurídicas, en los entes sin personalidad y de sus directivos. Op. cit., pp. 160-167.

${ }^{80}$ FeIJóo SÁnchez, B. El delito corporativo en el Código Penal Español. Op. cit., pp. 102 y ss. 
la evitación del resultado que sería precisamente la comisión de un delito por la persona física. Uno de los principales defensores de este planteamiento es RodRíGUez RAMOs ${ }^{81}$. Para este autor se partiría pues de que «la persona jurídica sólo puede incurrir en responsabilidad criminal como partícipe a título de cooperador necesario en régimen de comisión por omisión en un delito de los previstos a tal efecto en el Libro II del CP, protagonizado como autor material por una persona física que figure en la descripción del art. 31 bis del $\mathrm{CP} »$.

Sobre este planteamiento cabe decir, no obstante, que nos parece una interpretación muy forzada la que llega a plantear este autor, y que, además, implicaría —en el sentido que él lo expresa, siendo reconocido por él mismo- modificaciones de lege ferenda, no pareciendo concordar con la actual configuración que el artículo 31 bis desarrolla para las personas jurídicas ${ }^{82}$.

- Hay autores que sitúan el defecto de organización en el ámbito del injusto y en particular en sede de imputación objetiva.

Esta es la tesis mantenida por Gómez-JARA DíEz ${ }^{83}$ quien sitúa la ausencia de instrumentos de control en el plano del injusto, cerca del concepto del riesgo permitido y en consecuencia del análisis en que consiste la imputación objetiva. Este autor llega a afirmar que «la correcta ubicación del concepto de defecto de organización se sitúa en el ámbito del injusto - cuya determinación es normalmente objetiva- dejando al ámbito de la culpabilidad el lado más personal de la responsabilidad» y que «las medidas de control respecto del tipo delictivo concreto que ha institucionalizado una persona jurídica constituyen la base del injusto típico de la persona jurídica». La ausencia de instrumentos de prevención constituye un indicio relevante de que nos encontramos ante un defecto de organización, y permitirá apreciar «la existencia de un riesgo no permitido generado por la persona jurídica y, por tanto, la concurrencia del tipo objetivo en lo que se refiere al nivel de imputación de la conducta». Por el contrario, cuando una persona jurídica tenga establecidos «controles respecto de un riesgo penal específico que resultan idóneos para conjurar el mismo (...) existirá una atipicidad de la conducta de la persona jurídica».

81 Rodríguez Ramos, L. Sobre la culpabilidad de las personas jurídicas (al hilo de las sentencias SSTS 514/2015, 154 Y 221/2016). En Diario La Ley, núm. 8766, Sección Doctrina, 20 de mayo de 2016, p. 2.

82 Ibid., pp. 8-9.

83 Citado por Agudo Fernández, E; JaÉn Vallejo, M; Perrino Pérez, A.L. Capítulo IV. La responsabilidad penal de las personas jurídicas en la jurisprudencia. Op. cit., p. 164. 
Esta posición es criticada por ZuGALDÍA EsPINAR ${ }^{84}$ para quien este punto de vista «olvida, sin embargo, que también la mala organización empresarial es obra de las personas físicas qué actuando en el margen de las personas jurídicas, la han organizado deficientemente».

En este mismo sentido se expresa Bacigalupo Saggese quien señala que entre el riesgo generado por la ausencia de control debido o por la omisión de control, constitutivo de un déficit de organización, y el resultado creado o no evitado, expresado por el delito cometido por la persona física, debe haber una relación de imputación objetiva, rigiendo aquí los criterios generales de imputación ${ }^{85}$.

- Sugiere Zugaldía EsPINAR ${ }^{86}$, respecto al tipo objetivo, que «la acción de la persona jurídica consiste en el aumento del riesgo propio de la actividad de la empresa manifestado a través de la realización por parte de una persona física de un hecho típico de conexión que, por la forma de llevarse a cabo, sea al mismo tiempo jurídica, sociológica y criminológicamente expresión del específico actuar corporativo».

- La posición mayoritaria de los magistrados del Tribunal Supremo que pareciera dar a entender que el tipo objetivo de la responsabilidad penal de las personas jurídicas viene constituido por la cultura de cumplimiento de la persona jurídica. Esta posible interpretación chocaría frontalmente con los magistrados firmantes del Voto Particular en la sentencia del Tribunal Supremo núm. 154/2016, de 29 de febrero de 2016, quienes entienden que, incorporar al núcleo del tipo un elemento tan evanescente como la «ausencia de una cultura de respeto al Derecho» no cumple con el principio de certeza, -ínsito en el de tipicidad. Afirmación ésta desde todo punto de vista correcta, puesto que el principio de legalidad —nullum crimen, nulla poena sine praevia legia penale certa, scripta et stricta- contiene la garantía de lex certa que tiene que ver con la necesidad de absoluta determinación del supuesto de hecho previsto por la norma penal que define el delito; garantía que podría no respetarse si se admitiera como elemento del tipo objetivo la ausencia de una cultura de respeto al Derecho.

84 Zugaldía EsPinAR, J.M. La responsabilidad criminal de las personas jurídicas en el derecho penal español (análisis de la cuestión tras la reforma operada por la LO 1/201, de 30 de marzo). Op. cit., p. 224.

85 Bacigalupo Saggese, S. El modelo de imputación de la responsabilidad penal de los entes colectivos. Op cit. p. 84.

86 Zugaldía EsPinAR, J.M. La responsabilidad criminal de las personas jurídicas en el derecho penal español (análisis de la cuestión tras la reforma operada por la LO 1/201, de 30 de marzo). Op. cit., p. 224. 
Estos magistrados discrepantes, como se ha dicho, sitúan la tipicidad más cerca de las dos primeras letras del primer apartado del art. 31 bis CP.

\section{Y con respecto a la culpabilidad:}

- Bien podría concebirse sobre la base de la deficiente organización.

Valedor de esta posición es ZugALDía EsPINAR ${ }^{87}$ quien expresa que «respecto de la culpabilidad de la persona jurídica se requiere que la realización del hecho ilícito ocurra como consecuencia de haberse omitido - de forma contraria al deber - la adopción de alguna de las medidas de precaución y control que eran exigibles para garantizar el desarrollo legal (y no delictivo) de la actividad de la empresa (defecto de organización)» Se trata de prevenir «los defectos orgánicos —culpa in constituendo-, los defectos en la selección de los directivos — culpa in eligendo-y los defectos de control - culpa in vigilando-.

Así lo concibe BACigaLupo afirmando que la culpabilidad de la persona jurídica ha de basarse en un defecto de organización, por lo que tal culpabilidad debe excluirse «cuando ex ante el programa de compliance y/o un adecuado código de buen gobierno corporativo permite demostrar que en el seno de la organización de la persona jurídica se ha cumplido con el deber de cuidado exigido para la evitación de riesgos penales» ${ }^{88}$.

- O bien, sobre el concepto de cultura de respeto al Derecho. Para Gómez-JARA Díez la denominada cultura del respeto al Derecho queda fuera del injusto, asimilándose a lo que este autor denomina «cultura de compliance» (cultura de cumplimiento) vinculándola con la culpabilidad de la persona jurídica al expresar que «el planteamiento constructivista renuncia al concepto de defecto de organización en el ámbito de la culpabilidad para incidir en el aspecto relevante desde el punto de vista de la culpabilidad: la disposición jurídica del sujeto sobre el que se impone la pena. Dicha disposición jurídica se sintetiza en la cultura empresarial de cumplimiento o incumplimiento de la legalidad» ${ }^{89}$.

87 Zugaldía EsPinAR, J.M. La responsabilidad criminal de las personas jurídicas en el derecho penal español (análisis de la cuestión tras la reforma operada por la LO 1/2015, de 30 de marzo). Op. cit., p. 227. Igualmente, citando a SEelmann en Zugaldía EsPinar, J.M. La responsabilidad criminal de las personas jurídicas, de los entes sin personalidad y de sus directivos. Op. cit., pp. 55-56.

88 Bacigalupo SaggeSE, S. El modelo de imputación de la responsabilidad penal en los entes colectivos. Op. cit. p. 88. En este sentido vid., también, ZugaLdía EsPiNAR, J.M. La responsabilidad criminal de las personas jurídicas, de los entes sin personalidad y de sus directivos. Op. cit. pp. 97 y ss.

${ }^{89}$ Gómez-JARA DíEz, C. La culpabilidad de la persona jurídica. En Tratado de Responsabilidad de las personas jurídicas. Navarra: Thomsom Reuters, 2012, p. 169. 
- Por último, Rodríguez Ramos para concretar el contenido de la culpabilidad de las personas jurídicas, las sitúa en sede de la imputación subjetiva de la persona jurídica. Frente a la posibilidad de sustentarla en un nuevo concepto ajeno al dolo o la imprudencia, este autor parte de los tradicionales conceptos de dolo e imprudencia aplicados a la empresa ${ }^{90}$. Descartada una forma dolosa para las personas jurídicas, a su juicio, sí que se les podría imputar «negligencia corporativa (...) a los administradores, directivos o mandos intermedios que debieran haber evitado ese descuido previsible y evitable en cada caso concreto, aun cuando dicha persona no merezca sanción penal por cualquier motivo». Dicho autor apoya esta teoría por lo defendido en el Voto Particular, totalmente contraria a la decisión mayoritaria de la STS $154 / 2016$.

\section{Toma de posición}

Partimos como premisa de la idea de Zugaldía EsPINAR cuando afirma la importancia de elaborar una teoría jurídica del delito para la persona jurídica. Y es que, tal y como este autor plantea, con ello se puede determinar bajo qué condiciones un hecho es delito y si a su autor se le puede imponer una pena. En palabras de este autor «la finalidad de este esquema es garantizar la seguridad jurídica y la igualdad ante la ley en la aplicación del Derecho Penal haciendo de dicha aplicación algo racional (no emotivo), técnicamente aceptable (por su correcta fundamentación y argumentación legal), controlable (a través de un sistema de recursos ante los Tribunales) y predecible (ya que todos los operadores jurídicos van a resolver el caso aplicando las mismas reglas)» ${ }^{91}$.

Comprendiendo pues, la importancia de ejecutar esta labor corresponde ahora tomar posición. Pretendemos, por tanto, dar nuestro punto de vista acerca de la cuestión sobre cuál es la posible configuración del delito corporativo que ha reconocido nuestro Tribunal Supremo que esté más en concordancia con sus propios pronunciamientos, con los principios del derecho penal, así como con el propio tenor literal de la ley.

Perseguimos, en definitiva, dar una solución compatible con la función asignada a la dogmática jurídico-penal intentando, en consecuencia, establecer los presupuestos dogmáticos que permitan exigir responsabi-

90 Rodríguez Ramos, L. Sobre la culpabilidad de las personas jurídicas (al hilo de las STS 514/2015, 154 y 221/2016). Op. cit., pp. 4 y ss.

${ }_{91}$ Zugaldía EsPinaR, J. M. Teorías Jurídicas del delito de las personas jurídicas (aportaciones doctrinales y jurisprudenciales). Especial consideración de la teoría del hecho de conexión. Op. cit., p. 23. 
lidad criminal a las personas jurídicas en los términos previstos en los artículos 31 bis (y siguientes), y siempre procurando que sean lo más respetuosos posibles con la doctrina emanada del Tribunal Supremo.

Abordando pues, esta compleja labor, una primera cuestión esencial es la de establecer cual es el fundamento último de la responsabilidad penal de las personas jurídica. Partimos, por supuesto, de la base de que no parezca que haya un consenso ni jurisprudencial ni doctrinal acerca de qué fundamentaría en última instancia dicha responsabilidad.

$\mathrm{Y}$ es que existe una clara divergencia de opiniones entre lo mantenido por la Fiscalía General del Estado, lo mantenido por el Tribunal Supremo y por la multitud de autores que se han pronunciado sobre esta cuestión:

- Por un lado, un sector de la doctrina defiende que la responsabilidad penal de las personas jurídicas se sustenta en la conducta realizada por las personas físicas delimitadas en el artículo 31 bis CP. Esta es la posición defendida por la Circular 1/2016 y de RODRÍGUEZ RAMOS $^{92}$, entre otros autores.

- Otros autores son partidarios de defender otro fundamento: la implantación de una cultura de cumplimiento normativo. Este es, también, el posicionamiento de la STS 221/2016 y la STS 221/2016.

- Por otro lado, Gómez-Jara Díez ${ }^{93}$ defiende, que el delito de las personas físicas es el presupuesto, no el fundamento de la responsabilidad penal de las personas jurídicas ${ }^{94}$. Se podría utilizar varios razonamientos para defender este posicionamiento. Emplea este autor como argumentos, por un lado, que, si el delito de la persona física fuera el fundamento de la responsabilidad penal de las personas jurídicas que después, bajo determinadas circunstancias, se transfiriera a la persona jurídica, resultaría cuasi imposible el

92 Rodríguez Ramos, L. Sobre la culpabilidad de las personas jurídicas (al hilo de las STS 514/2015, 154 y 221/2016). Op. cit., pp. 1 y ss.

${ }_{93}$ Gómez-JARa DíEz, C. El pleno jurisdiccional del Tribunal Supremo sobre responsabilidad penal de las personas jurídicas: fundamentos, voces discrepantes y propuesta reconciliadora. Op. cit., p. 3.

${ }_{94}$ Así se deduce de la sentencia núm. 154/2016, Fundamento Jurídico Décimo, en la que se dice «En ambos motivos el Recurso incurre en una clara confusión acerca de la tipicidad de la intervención de la persona jurídica recurrente, que no estriba exclusivamente en la comisión del delito contra la salud pública atribuida a sus administradores, de hecho y de derecho, infracción que opera como requisito precedente necesario para el ulterior pronunciamiento acerca de la responsabilidad penal propia de la entidad medida en términos de incumplimiento de su obligación de poner los medios para la evitación de delitos en su seno». Continúa argumentando que «Una vez más procede la desestimación ya que también en este caso el Recurso incurre en el error, expuesto en su momento, de los restantes formalizados por las personas jurídicas condenadas, al confundir las conductas típicas de las personas físicas con el fundamento de la responsabilidad penal de las personas jurídicas». 
establecimiento de la responsabilidad cuando no pudiera individualizar persona física responsable penalmente. Y, por otro lado, resultaría difícilmente justificable que las circunstancias modificativas de la responsabilidad penal que afectan a la persona física - cuando pudiera individualizarse - no se transfirieran igualmente a la persona jurídica ${ }^{95}$. Por todo ello este autor sustenta la responsabilidad penal de las personas jurídicas en la existencia de un defecto organizativo en su seno.

- Por su parte, Feisóo Sánchez ${ }^{96}$ afirma que es indisociable el fundamento del delito corporativo con el fin de estimular un mayor cumplimiento de la legalidad. Continúa argumentando este autor que «se puede apreciar en el Código Penal, tras la reforma mediante la LO 1/2015 como la exención de responsabilidad tiene que ver claramente con elementos estructurales. Por consiguiente, el fundamento de la responsabilidad corporativa también debe tener un carácter estructural-organizativo con relación al cumplimiento de la legalidad penal $»^{97}$. Finalmente, estima que «el modelo español de responsabilidad corporativa se caracteriza por ser un modelo de co-responsabilidad en el que cada uno de los responsables del mismo hecho lo son por razones normativas distintas» y termina concluyendo «la conducta de la personas física que comete el delito forma parte del delito corporativo como presupuesto del mismo, pero no representa el fundamento de la responsabilidad penal de la persona jurídica» ${ }^{98}$.

- Por último, también se ha defendido que «el fundamento de la responsabilidad penal de las personas jurídicas se encontraría en el deber de prevenir determinados delitos» pero que "no obstante existirían determinados criterios que deberían tenerse en cuenta a la hora de fijar el nivel preventivo». Sin embargo, hay que tener presente que, tal y como el propio autor admite, defender esto "generaría una mayor inseguridad jurídica (...) cuando hablamos de las medidas preventivas a adoptar por las personas jurídicas, hablamos de una serie de controles y procesos muy variados, que carecen de desarrollo jurisprudencial ${ }^{99}$.

Consideramos, sin embargo, correcta la afirmación que realiza ZuGALDÍA ESPINAR de que «el modelo elegido tiene que ser el deducido de la

95 GÓMEZ-JARA DíEZ, C. El pleno jurisdiccional del Tribunal Supremo sobre responsabilidad penal de las personas jurídicas: fundamentos, voces discrepantes y propuesta reconciliadora. Op. cit., p. 3.

96 FeiJóo Sánchez, B. El delito corporativo en el Código Penal Español. Op.cit., p. 31.

97 Ibid., p. 77.

98 Ibid., p. 86.

99 GaLÁn Muñoz, A. Fundamentos y límites de la responsabilidad penal de las personas jurídicas tras la reforma de la LO1/2015. Op. cit., p. 297. 
ley penal, es decir, debe responder a una lectura posible de la misma» ${ }^{100}$. Y es que los argumentos utilizados por este autor son los que más identifican nuestra posición por su consistencia, su respeto a la ley penal, y, porque a través de ellos, podemos acercarnos a los planteamientos jurisprudenciales.

Y ello, en primer lugar, porque es que tal y como sostiene el mencionado autor, «el hecho de conexión - en torno al cual gira todo el sistema de «doble vía» de responsabilidad penal de las personas jurídicas del artículo 31 bis. 1, a) y b) - no puede entenderse como un elemento ajeno (o simple presupuesto) a la teoría jurídica del delito de personas jurídicas». No cabe duda de que la importancia que ha de tener este «hecho de conexión» ha de ocupar una posición transcendental o dominante en la nueva teoría jurídica del delito corporativo y no quedar relegado a un «mero presupuesto» Y ello se podría interpretar así, deducido del propio tenor literal de la ley:

- $\mathrm{Y}$ es que, efectivamente, como Zugaldía EsPinar ${ }^{101}$ apunta, no tendría mucho sentido hablar de presupuesto, tal y como el artículo 31 ter, $2 \mathrm{CP}$ expresamente reconoce, puesto que puede existir responsabilidad penal de las personas jurídicas sin que haya una previa responsabilidad criminal de la persona física.

- Pero, es más, el apartado que le antecede, esto es, el artículo 31 ter, $1 \mathrm{CP}$ establece como requisito exigible —entendido como esencial, añadiríamos- la constatación de la comisión de un delito "que haya tenido que cometerse por quien ostente los cargos o funciones aludidas en el artículo anterior, aun cuando la concreta persona física no haya sido individualizada o no haya sido posible dirigir un procedimiento contra ella».

Relegar, por tanto, el hecho de conexión a un mero papel de presupuesto - $\mathrm{a}$ un elemento ajeno o extraño, en palabras de ZugaLdía EsPINAR-, sería a nuestro entender desde todo punto de vista insostenible, atendiendo precisamente al tenor literal de estos artículos.

Por otra parte, respecto de entender que el fundamento de la responsabilidad de las personas jurídicas se encuentra en el concepto de «defecto

100 Zugaldía Espinar, J.M. Teorías Jurídicas del delito de las personas jurídicas (aportaciones doctrinales y jurisprudenciales). Especial consideración de la teoría del hecho de conexión. $O p$. cit., p. 24. De esta manera este autor defiende que la actuación del sujeto individual y la responsabilidad de la persona jurídica se efectúa a través del denominado «hecho de referencia» o «hecho de conexión», es decir, la realización por la persona física de un tipo penal en condiciones tales que permitan afirmar que constituye acción propia de la persona jurídica en cuyo provecho se actúa, y expresión de su específico obrar corporativo. Vid. también, en este sentido, BACigALUPo SAGGESE, S. La responsabilidad penal de los entes colectivos: el modelo de imputación del Código Penal. En Estudios de Derecho Penal. Homenaje al Profesor Miguel Bajo. Editorial Universitaria Ramón Areces. 2016. pp. 22 y 32.

101 Ibid., p. 24. 
de organización» o en el concepto de "cultura de respeto al derecho», ponemos de manifiesto lo expresado por DEL RosAL BLASCO ${ }^{102}$ cuando recuerda que las sentencias - y añadiríamos nosotros, algunos autores- hacen referencia a cuestiones tales como «defecto de organización», «cultura empresarial» $\mathrm{y}$ "cultura de cumplimiento o respeto a derecho», conceptos todos ellos ajenos al tenor literal del artículo 31 bis $1 \mathrm{CP}$, que, además, tienen un contenido muy confuso, muy controvertido a nivel doctrinal.

Bien es cierto, que las sentencias analizadas con anterioridad sí que aluden a que la fundamentación de la «responsabilidad penal de las personas jurídicas se encuentre en la ausencia de medidas eficaces de prevención y control» o a que el defecto estructural en los modelos de gestión, vigilancia y supervisión constituye el fundamento de la responsabilidad del delito corporativo ${ }^{103}$. Sin embargo, como bien apunta ZugaLdía EsPINAR «el defecto de organización no puede entenderse (de manera excluyente) como la única posibilidad de acción de las personas jurídicas» ${ }^{104}$, señalando que:

- La existencia de un defecto de organización (o, añadiríamos nosotros, «un defecto estructural»), de la persona jurídica es obra exclusivamente de las personas físicas que la han organizado deficientemente. Bien es cierto, podríamos llegar a entender, que, si en una persona jurídica no existen medidas de prevención y control, ello es consecuencia, de que las personas físicas que integran aquellas no han querido dotárselas.

- También, la cultura de respeto al derecho que ostenta una persona jurídica es, en realidad, la que le confieren las personas físicas que actúan en su seno.

Y es que aunque en el propio Preámbulo de la Reforma de la Ley Orgánica 1/2015 —excluyendo el concepto de cultura de respeto al derecho- se viene a decir que la finalidad de la misma es «delimitar adecuadamente el contenido del «debido control», cuyo quebrantamiento permite fundamentar su responsabilidad penal», como este autor apunta lo que fundamenta la responsabilidad criminal es la culpabilidad de la persona jurídica (lo que se vincula a la infracción del debido control, esto es, al defecto de organización)» ${ }^{105}$. Y, como ya hemos señalado anterior-

102 Del Rosal Blasco, B. Sobre los elementos estructurales de la responsabilidad penal de las personas jurídicas: reflexiones sobre las SSTS 154/2016 Y 221/2016 y sobre la Circular núm. 1/2016 de la Fiscalía General del Estado. Op. cit., p. 10.

103 Fundamento de Derecho Quinto de la primera sentencia contenida en la STS núm. 221/2016, de 16 de marzo.

${ }_{104}$ Zugaldía EsPinar, J.M. Teorías Jurídicas del delito de las personas jurídicas (aportaciones doctrinales y jurisprudenciales). Especial consideración de la teoría del hecho de conexión. Op. cit., p. 24.

105 Zugaldía EsPinar, J.M. La responsabilidad criminal de las personas jurídicas, de los entes sin personalidad y de sus directivos. Op. cit., p. 86. 
mente, nos mostramos del todo de acuerdo en que la existencia de este defecto de organización es consecuencia del, podríamos llamar, «mal obrar» o «mal diligenciar» de las personas físicas que integran la misma.

Por ello, nos adherimos a lo propuesto por este autor cuando llegar a establecer que «En efecto: la fundamentación criminal de la persona jurídica está necesariamente vinculada a las acciones de las personas físicas que las gobiernan y que por ellas y para ellas actúan, dominando su voluntad y sus decisiones en el mercado y en la sociedad» ${ }^{106}$. Y es que como bien dice este autor «un defecto de organización empresarial exige, del mismo modo, que alguien haya organizado la empresa defectuosamente (la empresa no se organiza sola)» ${ }^{107}$. Por ello, se puede sostener que el artículo 31 bis CP parece apuntar al modelo del hecho de referencia o del hecho de conexión.

En definitiva, podríamos hablar de una responsabilidad criminal directa por la propia acción y por la propia culpabilidad de la persona jurídica. Por ello, de forma paralela al delito de las personas físicas, puede definirse el delito corporativo como un hecho ilícito (típico y antijurídico) realizado por autor culpable, mostrando cada uno de estos conceptos, unas genuinas características:

- Con relación a la autoría, se prevé, en el actual modelo, un sistema de doble autoría ${ }^{108}$ :

- Por un lado, los representantes legales o personas autorizadas para la toma de decisiones o que tengan facultades de organización y control, cuyos hechos punibles son imputables a la persona jurídica.

- Y, por otro lado, los que están sometidos a la autoridad de los anteriores, por cuyos hechos responde también la persona jurídica, sino se ha ejercido sobre ellos el debido control.

- En relación con el tipo objetivo de la tipicidad ${ }^{109}$ :

- La acción de la persona jurídica consistiría en el incremento del riesgo propio de la actividad de la empresa manifestado a través de la realización por parte de las personas físicas de un hecho típico de conexión - coincidiendo en este aspecto con lo manifestado por los integrantes del Voto Particular de la STS núm. 154/2016 - que, por la forma de llevarse a cabo, sea al mismo tiempo jurídica, sociológica y criminológicamente

106 Ibid., pp. 66-67.

107 Ibid., p. 67.

108 Agudo Fernández, E; JaÉn Vallejo, M; Perrino Pérez, A.L. Capítulo IV. La responsabilidad penal de las personas jurídicas en la jurisprudencia. Op. cit., p. 46.

$109 \mathrm{Vid}$., con mayor profundidad, Zugaldía EsPinar, J, M. La responsabilidad criminal de las personas jurídicas, de los entes sin personalidad y de sus directivos. Op. cit., pp. 70 y ss. 
expresión del específico actuar corporativo ${ }^{110}$, siempre que se cumplieran los requisitos contemplados en el artículo 31 bis. Nos mostramos de acuerdo con Zugaldía EsPINAR ${ }^{111}$ cuando argumenta que «si la conducta típica de las personas jurídica consistiera en la ausencia (o déficit) de modelos de control, absolutamente todos los delitos de las personas jurídicas serían siempre el mismo, esto es, el de haberse organizado mal».

- Con relación al tipo subjetivo de la tipicidad:

- El carácter doloso o imprudente de la responsabilidad de la persona jurídica debe tener como punto de referencia el carácter doloso o imprudente del hecho de conexión realizado por la persona física ${ }^{112}$. Y es que como bien señala este autor «la admisión de responsabilidad criminal de las personas jurídicas en algunos delitos imprudentes apunta a la necesidad de ubicar el dolo o la imprudencia de la persona jurídica en el hecho de conexión, esto es el hecho típico de la persona física, puesto que, la imprudencia y el dolo son categorías dogmáticas ontológicamente incompatibles con las personas jurídicas» ${ }^{113}$.

- En cuanto a la antijuridicidad.

- Cabría la posibilidad de que la persona jurídica está exenta de responsabilidad criminal si concurre a su favor una causa de justificación. Siempre que, tal y como indica ZugaLdía EsPI$\mathrm{NAR}^{114}$, exista un conflicto de intereses en los que estén en juego los de las personas jurídicas y que se resuelva en interés de ésta.

- Por último, respecto a la culpabilidad.

- Se requiere que «la realización del hecho ilícito ocurra como consecuencia de haberse omitido - de forma contraria al

110 ZugaLdía EsPinAR, J.M. La responsabilidad criminal de las personas jurídicas en el derecho penal español (análisis de la cuestión tras la reforma operada por la LO 1/201, de 30 de marzo). Op. cit., pp. 223-224 El autor, citando a TiedEMANn, afirma que «el citado modelo parte de considerar que la conducta típica de la persona jurídica se expresa a través de la conducta típica de una persona física. Y es que no es posible prescindir de la persona física para determinar la responsabilidad criminal de las personas jurídicas».

111 Zugaldía EsPinar, J.M. Teorías Jurídicas del delito de las personas jurídicas (aportaciones doctrinales y jurisprudenciales). Especial consideración de la teoría del hecho de conexión. Op. cit., p. 24.

112 Bacigalupo Zapater, citado por Zugaldía Espinar, J.M. Teorías Jurídicas del delito de las personas jurídicas (aportaciones doctrinales y jurisprudenciales). Especial consideración de la teoría del hecho de conexión. Op. cit., p. 27.

113 Zugaldía EsPinaR, J.M. Teorías Jurídicas del delito de las personas jurídicas (aportaciones doctrinales y jurisprudenciales). Especial consideración de la teoría del hecho de conexión. Op. cit., p. 24.

114 Ibid., p. 28. 
deber- la adopción de alguna de las medidas de precaución y control que eran exigibles para garantizar el desarrollo legal (y no delictivo) de la actividad de la empresa (defecto de organización)» ${ }^{115}$. Lo que TIEDEMANN ${ }^{116}$ ha entendido como la omisión contraria a un recto proceder de alguna de las medidas de precaución y control exigibles para garantizar el desarrollo ajustado a Derecho a la actividad de la empresa.

- En definitiva, se trata de prevenir defectos orgánicos ${ }^{117} \_$culpa in constituendo, culpa in eligendo vel in instruendo y culpa in vigilando-. Se coincide, en este sentido, con el planteamiento de la culpabilidad por parte de los magistrados firmantes del Voto Particular STS núm. 154/2016 pues ésta se fundamentaría en «la "culpa in eligendo» y la "culpa in vigilando», o incluso si se quiere profundizar más, de culpa «in constituendo» y la culpa «in instruendo».

- Por último, coincidiríamos con FeIJóo SÁnchez, cuando identifica el fundamento de la exención de la responsabilidad criminal de las personas jurídicas en la presencia en la organización de los Programas de Cumplimiento Normativo. Y es que resulta acertado cuando el autor afirma que «es lógico que la implantación e institucionalización de un programa de cumplimiento normativo por parte de los administradores y responsables de cumplimiento tenga efectos beneficiosos para la persona jurídica, exonerándoles de la responsabilidad» ${ }^{118}$. También en este sentido hay que tener en cuenta que - tal y como ocurre con el fundamento de la responsabilidad penal de las personas jurídicas- la exención no puede ser entendida sin «el factor humano».

\section{Unas reflexiones a modo de conclusión}

1. La eclosión en los últimos años de nuevas manifestaciones de delincuencia económica ha propiciado que se tenga que recurrir a nuevas formas de responsabilidad criminal, extendiéndola a nuevos sujetos. Surge, en este contexto, la regulación en España

115 Ibid., p. 28.

116 Autor citado por Sáenz Soubrier, J. J. La responsabilidad penal de las personas jurídicas. En: Aspectos Prácticos de la Responsabilidad Criminal de las Personas Jurídicas. Op. cit., p. 115.

117 Zugaldía EsPinaR, J.M. Teorías Jurídicas del delito de las personas jurídicas (aportaciones doctrinales y jurisprudenciales). Especial consideración de la teoría del hecho de conexión. Op. cit., pp. 28-29.

118 Feijóo Sánchez, B. El delito corporativo en el Código Penal Español. Op. cit., p. 76. 
de una auténtica responsabilidad de las personas jurídicas con el propósito de abordar determinados supuestos delictivos en donde la persecución penal a la persona física resulta muy complicada, sino imposible - teniéndose que recurrir a la condena de estructuras organizativas con el fin de evitar la impunidad de estos comportamientos-.

2. En este sentido, la regulación que surge tras las reformas operadas en el Código Penal en los años 2010 y 2015 resultaba más que necesaria. Paulatinamente, el Tribunal Supremo ha ido publicando diversas sentencias que regulan esta cuestión y, como primer punto de partida, podemos afirmar que el denominador común de todas ellas es el reconocimiento, con toda claridad, de la vigencia de los principios esenciales del Derecho penal también en la configuración del régimen de responsabilidad penal de las personas jurídicas.

3. Una segunda idea que subyace a todas ellas es una evidente resistencia a todo modelo de responsabilidad vicarial o por transferencia, en una clara contraposición con la tesis de la Fiscalía General del Estado, quedando excluida toda clase de responsabilidad objetiva o de responsabilidad por un hecho que no sea propio. Y es que, para el Tribunal Supremo el único modelo compatible con el principio de culpabilidad en el modelo de autorresponsabilidad en la que lo relevante es la propia culpabilidad de la entidad.

4. Un tercer hito en esta jurisprudencia de nuestro Alto Tribunal es, a nuestro modo de ver, un reconocimiento de un «Delito Corporativo» diferenciado, en el contenido de su estructura del delito que comete la persona física. Nos encontramos, en consecuencia, con una estructura genuina del delito cometido por la persona jurídica, con su propio injusto y con su propia culpabilidad.

5. Debemos también destacar, el interés mostrado en estas sentencias del Tribunal Supremo, por desembrollar cuál ha de ser el fundamento que ha de predominar en la responsabilidad penal de las personas jurídicas. Y, aunque, es cierto que las sentencias afirmen, en este sentido, que «el defecto estructural en los modelos de gestión, vigilancia y supervisión constituye el fundamento de la responsabilidad del delito corporativo» o que el propio Preámbulo de la Ley Orgánica 1/2015 alude a que la finalidad de la misma es «delimitar adecuadamente el contenido del «debido control», cuyo quebrantamiento permite fundamentar su responsabilidad penal», lo cierto es que, si recapacitamos detenidamente sobre esta idea, la existencia de este defecto de organización es consecuencia del, podríamos llamar, «mal obrar» $\mathrm{o}$ «mal diligenciar» de las personas físicas que integran la misma. En este sentido, hemos excluido que la comisión de un delito por parte de la persona física integrante 
de la organización constituya un mero presupuesto o «elemento ajeno» en el régimen de responsabilidad de las personas jurídicas, sino que constituye su auténtico fundamento.

6. Hemos, también, dado cuenta de la presencia de una importante división acerca de la estructura concreta del delito corporativo, por parte de la doctrina a raíz de estos pronunciamientos del Tribunal Supremo. En este sentido, hemos puesto de relieve como:

a. A nivel de injusto, algunos autores sitúan el defecto de organización, o la ausencia de medidas de control idóneas para evitar el delito; mientras que otros vienen a entender que el tipo objetivo de la responsabilidad penal de las personas jurídicas viene constituido por la cultura de cumplimiento de la persona jurídica. Están también, los autores que interpretan que el artículo 31 bis configura una modalidad de participación delictiva realizada en régimen de comisión por omisión (artículo $11 \mathrm{CP}$ ), y los que identifican el tipo con la realización por parte de las personas físicas de un hecho de conexión. No obstante, la jurisprudencia analizada no deja lo suficientemente claro cuál es su posición a este respecto, ni tampoco sobre como hemos de entender el dolo o la imprudencia de la persona jurídica.

b. A nivel de culpabilidad, la Sala Segunda reconoce una culpabilidad propia, pero, sin embargo, no llega a delimitar, con suficiente precisión, cómo hemos de entender este concepto. Así las cosas, al igual que ocurre con el injusto, han surgido diversas teorías doctrinales acerca de cómo ha de concebirse dicha culpabilidad: si por un defecto en la organización, por falta de cultura de cumplimiento, etc.

7. Además, hemos tenido también la ocasión de observar, cómo respaldar un modelo u otro tiene consecuencias prácticas procesales de indudable trascendencia en el ámbito de la carga probatoria. Por un lado, si se considera que en la tipicidad del delito corporativo está configurada por el defecto de organización, le corresponde a la acusación acreditar la inexistencia de tales controles y en consecuencia si ésta no es capaz de demostrarlo, podría no llegarse a abrir la causa penal o, de hacerse, ésta podría quedar sobreseída de forma prematura. Por otro lado, si se parte de la base de que el tipo está constituido por el hecho de conexión, es decir, por lo establecido en las dos primeras letras del primer apartado del art. 31 bis CP, lo que le correspondería probar a la acusación son los elementos recogidos en este precepto, no la inexistencia de un defecto de organización o la ausencia de una cultura de respeto al derecho. Le atañería a la empresa, en este supuesto, probar la concurrencia de los instrumentos adecuados y eficaces de prevención del delito. 
8. Frente a todas estas concepciones, nosotros defendemos, que el artículo 31 bis CP apunta al modelo del hecho de referencia o del hecho de conexión - atendiendo al fundamento de la responsabilidad penal de las personas jurídicas, al propio tenor literal de la ley e intentando ser coherentes e integrar los pronunciamientos del Tribunal Supremo- - Por ello, siguiendo el modelo que propone ZugALDÍA ESPINAR en la responsabilidad criminal directa de la persona jurídica, éste responde por su propia acción —entendida ésta por el incremento del riesgo propio de la actividad de la empresa manifestado a través de la realización por parte de las personas físicas de un hecho típico de conexión-y por su propia culpabilidad -entendida ésta como la realización del hecho ilícito, consecuencia de haberse omitido, de forma contraria al deber, la adopción de alguna de las medidas de precaución y control que eran exigibles para garantizar el desarrollo legal de la actividad de la empresa-.

9. En definitiva, y pese a lo afirmado previamente, somos conscientes, de que nuestro modelo de responsabilidad penal de las personas jurídicas se encuentra en una fase inicial, esto es, aún en construcción. La dogmática y la jurisprudencia se enfrentan a un atractivo a la par que desafiante reto, como es el de elaborar el modelo de responsabilidad penal de las personas jurídicas y dar respuesta a las cuestiones sustantivas y procesales que plantea. Estaremos pendientes, por tanto, a cómo el Tribunal Supremo va consolidando unas pautas y criterios de cómo ha de entenderse la responsabilidad penal de las personas jurídicas. 